\title{
Neurociência e Ensino de Física: limites e possibilidades em um campo inexplorado
}

\author{
Neuroscience and Physics Teaching: limits and possibilities in an unexplored field \\ Guilherme Brockington ${ }^{* 10}$ \\ ${ }^{1}$ Universidade Federal do ABC, Centro de Ciências Naturais e Humanas, Santo André, SP, Brasil.
}

Recebido em 6 de outubro de 2020. Aceito em 3 de dezembro de 2020.

\begin{abstract}
Há algumas décadas, surgiu um novo campo de investigações na interface entre Neurociência e Educação. A motivação central desta área de pesquisa é o estudo dos mecanismos neurais que sustentam a aprendizagem, buscando compreender de maneira mais complexa como ocorre o processo de aquisição e uso do conhecimento. Espera-se também que possíveis achados nestas pesquisas contribuam para a melhoria na qualidade do processo de ensino. Diversas descobertas vêm sendo feitas nesses anos, mudando antigas concepções acerca de vários processos cognitivos diretamente envolvidos na construção do pensamento físico. Entretanto, estes resultados são praticamente desconhecidos na área de Ensino de Física. Assim, o objetivo deste artigo é apresentar pesquisas que revelam os limites e possibilidades do uso da Neurociência em investigações voltadas para a aprendizagem de Física.
\end{abstract}

Palavras-chave: Neurociência, Neuroeducação, Cognição.

A few decades ago, a new field of research emerged at the interface between Neuroscience and Education. The central motivation of this research area is the study of the neural mechanisms that support learning, seeking to understand in a more complex way how the process of knowledge acquisition and its use occurs. It is also expected that possible findings from these studies will contribute to an improvement in the quality of the teaching process. Several discoveries made in those years changed old conceptions about various cognitive processes involved in the construction of physical thinking. However, these results are practically unknown in the area of Physics Education. Thus, the aim of this article is to present researches that reveal the limits and possibilities of the use of Neuroscience in investigations aimed at learning Physics.

Keywords: Neuroscience, Neuroeducation, Cognition.

\section{Introdução}

Neurociência e Educação, enquanto um campo integrado de pesquisa, é um empreendimento recente e em rápido crescimento. Enquanto área, a interface entre esses dois conjuntos de conhecimentos recebe nomes como "neurociência educacional" ou "neuroeducação", ainda sem consenso entre pesquisadores. De qualquer modo, o principal objetivo da criação desse novo campo de investigação é, a partir do estudo dos mecanismos neurais que sustentam a aprendizagem, compreender de maneira profunda como ocorre o processo de aquisição e uso do conhecimento [1-5]. A expectativa é que juntando as descobertas recentes advindas dos estudos do funcionamento do cérebro com as teorias psicológicas e educacionais possa se obter um quadro claro, mais preciso, sobre como, de fato, alguém aprende alguma coisa, de conteúdos abstratos até o controle motor, passando por aritmética e alfabetização. Nesse cenário, também se espera que resultados de pesquisa desse novo campo possam orientar aplicações práticas na sala de

\footnotetext{
*Endereço de correspondência: ensinodefisica@gmail.com
}

aula, a fim de melhorar a aprendizagem e impactar nos resultados educacionais.

Nos anos 1990, na chamada "década do cérebro" [6], graças, principalmente, aos avanços tecnológicos na produção de imagens cerebrais in vivo, houve uma explosão na quantidade de pesquisas que investigam, cientificamente, a relação mente e cérebro. Além disso, a partir desse período, houve um crescimento vertiginoso na percepção pública da Neurociência. É justamente no bojo dessa produção massiva de novos conhecimentos acerca do funcionamento cerebral e do alargamento no interesse sobre o tema para fora dos laboratórios de neurologia que nasce a interface Neurociência e Educação, enquanto campo específico de pesquisas voltadas à melhoria na qualidade do processo de ensino e aprendizagem [7, 8. Desde então, o crescimento dessa área levou revistas científicas tradicionais, como Science e Nature, a abordar temas educacionais. Mais que isso, novos periódicos foram criados para o tratamento exclusivo do tema, como "Nature - Science of Learning", "Trends in Neuroscience and Education", "Mind, Brain and Education", "Educational Neuroscience" entre outros, todos abordando pesquisas na interface Neurociência, 
Psicologia e Educação. Além disso, novas sociedades e grupos de pesquisa foram criados, como o "International Mind, Brain and Education Society (IMBES)", e universidades como Harvard, Stanford, Yale, London, Cambridge e Bristol criaram cursos de pós-graduação específicos em Neurociência e Educação. Temos, assim, uma área em franca ascensão, repleta de desafios.

Entretanto, surgem também críticas que questionam a extensão e, até mesmo, a validade de se dedicar esforços que pretendem utilizar as pesquisas em Neurociências para subsidiar processos educacionais. A crítica mais relevante surge, justamente, quando se depara com o maior desafio enfrentado pela área: levar as evidências geradas em laboratórios, em geral advindas de experimentos altamente controlados e muito distantes da sala de aula real, para o ambiente escolar. Desta forma, para alguns pesquisadores, a conexão entre Neurociência e Educação está extremamente longe de se tornar viável. John Bruer, um dos maiores representantes desta vertente, publicou, em 1997, um artigo intitulado "Education and the brain: A bridge too far" no qual afirma acreditar que a neurociência, possivelmente, nunca contribuirá para a educação [9]. Para ele, há uma completa desarticulação de conhecimentos entre as duas áreas, de modo que

"as tentativas de ligar neurobiologia com o desenvolvimento do cérebro e educação ignoram, ou são inconsistentes, com o que a psicologia cognitiva nos diz sobre ensino e aprendizagem. [...] Os métodos de neurociência celular e molecular são poderosos, mas nem sempre fica claro que os conceitos de aprendizagem e memória utilizados por neurocientistas não são os mesmos utilizados pelos psicólogos, e muito menos pelos professores". [10], pg 104, tradução nossa).

Segundo Bruer, somente a Psicologia Cognitiva é capaz de contribuir para o estabelecimento de uma ciência da aprendizagem [911. Ele acha frustrante que pesquisadores em Educação estejam fascinados pelas descobertas da Neurociência e passam a menosprezar o corpo de conhecimento adquirido até o momento pelos estudos em Psicologia. Contudo, as críticas severas apresentadas por Bruer devem ser analisadas considerando o contexto no qual se encontram. Talvez esta seja uma reação ao uso inadequado de alguns resultados que originaram diversas especulações por parte da mídia americana e inglesa. Como ele relata, resultados de uma pesquisa sobre o crescimento de massa cinzenta durante a adolescência sugeriram a existência de uma nova fase de grande produção sináptica. A apropriação irrefletida destes resultados para o campo da Educação gerou uma série de especulações absurdas, completamente equivocadas do ponto de vista científico. É bastante provável que tamanho pessimismo decorra da opção do autor em se ater apenas ao uso inadequado e sensacionalista de diferentes resultados de pesquisa que tentam, na verdade, fazer com que a Neurociência seja tratada como a panacéia da Educação. Há, nos EUA e em parte da Europa o crescimento de uma indústria de programas educacionais chamados de "brain-based", que se utilizam destas especulações para vender seus produtos, que vão desde ginástica para o cérebro, passando por pílulas de Omega 3 e chegando à prescrição de músicas de Mozart para deixar os bebês mais inteligentes [12 15]. No Brasil, ainda que em menor escala, esse fenômeno também está acontecendo, com a venda de livros, cursos online e até formação para rede pública, vendendo uma série de inverdades e ilusões, bastando para isso apenas o acréscimo do prefixo neuro como garantia de qualidade.

Seguindo essa metáfora de uma ponte unindo dois campos de pesquisa, Dougherty e Robey publicaram, em 2018, um artigo afirmando que acreditam que a expectativa de que achados da Neurociência possam contribuir com a Educação é forçada e mal direcionada [16]. No artigo, considera-se que embora exista muito valor na compreensão dos mecanismos cerebrais gerada pela Neurociência, tal entendimento seria completamente desnecessário para o desenvolvimento de intervenções eficazes na escola. Segundo os autores, para se melhorar a aprendizagem não é necessário a compreensão de seus mecanismos, mas simplesmente investigar o comportamento dos estudantes nos ambientes de ensino: "Compreender o comportamento é necessário e suficiente para orientar o desenvolvimento de intervenções educacionais; compreender o cérebro, não" ([16] pg 402, tradução nossa). Com uma definição bem limitada de aprendizagem, os autores usam como exemplo tarefas de memorização e dizem que seria mas eficaz financiar pesquisas em terapia comportamental. O texto acaba por apresentar como argumento principal uma visão, no mínimo, ultrapassada, pautada em uma compreensão quase behaviorista do processo educacional, principalmente, quando usam o termo "treinamento cerebral" como se fosse esse o objetivo principal das intervenções pedagógicas.

A fragilidade dos argumentos de Dougherty e Robey levaram à publicação, pela mesma revista, de uma "resposta", na qual Thomas apresenta não só a superficialidade das afirmações dos autores como aponta caminhos para o avanço desse campo de pesquisa, usando no título de seu artigo uma expressão divertida: "chega de metáforas de ponte" [17]. O autor argumenta que para a maior compreensão dos processos educacionais é preciso que haja uma interdisciplinaridade de fato, ao invés de se buscar disciplinas isoladas, específicas, supostamente capazes de, sozinhas, contribuírem para a melhoria da aprendizagem escolar. Mais que isso, ele argumenta o quão contraproducente é esta rixa entre as áreas de pesquisa, que leva não somente à divisão, mas, principalmente, à impossibilidade de estudar a aprendizagem de maneira complexa, conectando mecanismo e comportamento, psiquismo e estruturas cerebrais. "A pesquisa interdisciplinar trata da integração 
de restrições de vários níveis de descrição para produzir melhores teorias em todos os níveis." ([17] pg 1, tradução nossa).

O autor traz críticas legítimas à neuroeducação: como a possibilidade de haver apenas a criação de novos nomes para processos já descritos há tempos pela Psicologia ou Educação; a necessidade do entendimento de que a aprendizagem é apenas um elemento do processo educacional, sendo preciso também considerar as variáveis políticas e socioeconômicas; a necessidade de se promover um diálogo real, ouvindo os professores, o que não ocorre na prática, entre outros pontos centrais de uma análise crítica da interface entre Neurociência e Educação. Além disso, Thomas afirma que também existem críticas espúrias: como a defesa que somente a Neurociência, sem a Psicologia, poderá contribuir com a Educação; a defesa de que apenas pesquisas originais são importantes, descartando muito do que já se conhece no campo educacional e a ideia de que o cérebro é tão complexo que é impossível de compreendê-lo. O autor termina, uma vez mais, fazendo uma defesa profunda da interdisciplinaridade.

Por outro lado, inúmeros pesquisadores defendem as pesquisas em Neurociência e Educação. Cabe destaque ao influente artigo de Sigman e colaboradores, publicado em 2014 na Nature Neurosciences [4. Nele, os autores não só defendem que se centrem esforços e financiamento para pesquisas na área como apresentam quatro casos específicos em que a Neurociência, juntamente com outras disciplinas, contribui para orientar os processos educacionais. São apresentados exemplos nos quais variando aspectos fisiológicos como nutrição, exercícios e sono tem-se ganhos expressivos na aprendizagem. Além disso, são discutidos como arquiteturas cerebrais moldam a aquisição de linguagem e leitura, permitindo uma compreensão, até então, inédita desses processos. Finalmente, os autores apresentam ferramentas da Neurociência que permitem a detecção precoce de déficits cognitivos, mesmo em bebês, permitindo a busca por intervenções cada vez mais cedo.

Sem dúvida alguma, os resultados obtidos pela Neurociência devem ser recebidos com cuidado pelos educadores. Qualquer pesquisador que trave um contato minimamente aprofundado com estas pesquisas pode perceber a complexidade de transpô-las diretamente para a sala de aula. Contudo, é preciso considerar que transladar resultados de pesquisas científicas para o contexto escolar é uma tarefa complexa, mesmo para áreas do conhecimento há muito estabelecidas, como a Psicologia. Em um artigo importante para essa discussão destaca-se [18], no qual o autor alerta que técnicas como marcar texto ou sublinhá-lo, ainda que com diversas evidências acerca de sua ineficácia na aprendizagem, continuam como parte cotidiana da atividade de estudo. Já o uso sistemático de testes, cuja eficácia é suportada por inúmeros resultados de pesquisa, não se tornou uma prática recorrente entre os estudantes. Isso significa que mesmo estabelecida há centenas de anos, há uma grande dificuldade em se transpor para a prática pedagógica aquilo que se encontra nas pesquisas em Psicologia, de modo que não teria como ser diferente com a Neurociência.

Assim, mais do que a ânsia de buscar resultados da Neurociência para serem transformados diretamente em práticas pedagógicas, será defendido nesse texto o potencial que todo o arcabouço teórico-metodológico das ciências do cérebro tem para oferecer uma nova via para as pesquisas em Ensino de Física. Quando se pensa no conhecimento físico, o desafio imposto à "Neurociência e Educação" toma matizes ainda mais complexas. Basta refletir sobre os inúmeros esforços feitos pela área ao longo das últimas décadas, revelando diferentes dificuldades existentes na compreensão dos processos de construção dos conteúdos da Física em situações de ensino-aprendizagem. Mais que isso, há tempos que inúmeros grupos de pesquisa investigam quais são os condicionantes para que os estudantes incorporem tais conhecimentos em sua estrutura interpretativa. Desta forma, a utilização do arcabouço teórico-metodológico da Neurociência revela possibilidades interessantes e inovadoras de investigação de velhos problemas conhecidos na área.

Neste artigo, então, serão apresentadas e discutidas diferentes pesquisas seminais nesse novo campo de investigação e que abordam alguns temas centrais que podem ser utilizados nas pesquisas em Ensino de Física. A ideia não é apresentar uma revisão bibliográfica, mas permitir que pesquisadores da área possam não só se familiarizem com o que é produzido atualmente, mas, principalmente, convidá-los a se aprofundarem na Neurociência e Educação centrando esforços para o desenvolvimento de investigações sobre o ensino e aprendizagem da Física. Mais que buscar a transformação direta da prática na sala de aula, defendo que os trabalhos nesta interface podem ser utilizados para se discutir temas mais abrangentes, contribuindo para um entendimento mais profundo, baseado em evidências, sobre os mecanismos cerebrais, psicológicos e pedagógicos envolvidos nos processos de aquisição e uso do conhecimento físico, de uma maneira diferente do que foi realizado até agora.

\section{Neurociência e Aprendizagem}

Atualmente, a Neurociência fornece um novo entendimento acerca de diferentes processos cognitivos e desvenda as propriedades neurais que dão suporte à linguagem, ao entendimento aritmético, à realização de cálculos etc. 19 26. Assim, já há algum tempo, muitos dos elementos centrais do desenvolvimento e apropriação do conhecimento científico vem sendo largamente investigados.

Métodos não invasivos como medidas psicofisiológicas (alterações fisiológicas relacionadas a processos cognitivos emocionais, como mudança na frequência cardíaca 
ou aumento da produção das glândulas endócrinas), formação de imagens por Ressonância Magnética funcional (IRMf), Tomografia por Emissão de Pósitron (TEP) e Eletroencefalografia (EEG) vêm sendo utilizados para perscrutar o cérebro, mudando antigas concepções sobre diversas funções cognitivas, com implicações importantes para a Educação [27 29].

Estes conhecimentos, principalmente, a partir da tecnologia de neuroimagem, ampliaram a compreensão sobre o funcionamento de diferentes processos cognitivos, em especial a aprendizagem. Estudos seminais revelaram que o ato de aprender está, necessariamente, acompanhado de diferentes modificações cerebrais, identificando atividades de determinadas redes neurais que influenciam e guiam diferentes modelos de cognição [20, 29, 30].

Desta forma, compreender estes modelos pode conduzir a um melhor e mais profundo entendimento dos processos cognitivos envolvidos na aprendizagem. Neste contexto, entende-se a aprendizagem como o fortalecimento ou enfraquecimento das conexões neuronais, as quais têm seus padrões conectivos alterados a todo o momento em resposta aos estímulos externos, às nossas percepções, pensamentos e ações, num complexo que mistura biologia, psiquismo e cultura [31,34]. O entendimento sobre algumas funções cognitivas, como atenção e memória, tem crescido a cada ano, de modo que processos complexos subjacentes à fala, à linguagem, ao pensamento, ao raciocínio, à leitura e ao uso da Matemática tornam-se cada vez mais conhecidos. Tais avanços, entretanto, são ainda pouco conhecidos na área de Ensino e, por consequência, pouco utilizados pelos pesquisadores.

Certamente, os educadores não precisam compreender ou mesmo considerar a aprendizagem ao nível celular para realizar o trabalho docente mais cotidiano. É indiscutível que a eficácia de um processo educacional é determinada também por outros fatores que não os biológicos. As pesquisas em Educação mostraram, há tempos, a influência das relações professor-alunosaber, bem como a dependência do contexto familiar, escolar, social e econômico nos processos de ensino e aprendizagem. Sendo assim, é preciso ressaltar que, de maneira alguma, pretende-se reduzir a complexidade envolvida nos processos educacionais a seus elementos neuronais.

Entretanto, deve-se concordar que toda vez que se fala em aprendizagem, direta ou indiretamente, falase sobre o desenvolvimento do cérebro, ou seja, todo processo educacional está íntima e fortemente ligado a mudanças no córtex. A aprendizagem, de maneira geral, diz respeito a alterações na conectividade entre os neurônios, seja por meio de mudanças na potencialização das sinapses ou por meio do reforço de conexões. Um ensino eficaz, então, deve afetar diretamente as funções cerebrais. Neste sentido, a aprendizagem é o processo pelo qual o cérebro reage aos estímulos externos e internos, fortalecendo algumas sinapses e enfraquecendo outras.
Desta maneira, os diferentes padrões de atividade neural podem ser pensados como correspondentes a diferentes estados mentais ou representações mentais.

Deste modo, investigações mais profundas acerca dos diferentes processos de aprendizagem proporcionam a possibilidade de compreender os processos educativos de uma forma absurdamente distinta do que tem sido feito até o momento, propiciando a conexão ideal entre Educação e Neurociência. A compreensão de como as informações retiradas do ambiente para construir as representações física do mundo são codificadas no cérebro podem dar pistas importantes sobre a aprendizagem de conteúdos científicos, conhecimento impossível de ser obtido de outra forma.

Com o avanço das investigações sobre o funcionamento do cérebro, tem surgido uma proliferação de opiniões sobre descobertas da neurociência cognitiva que podem ter ligação com a prática educativa. Geralmente, tratamse de pesquisas que revelam mudanças estruturais e funcionais no cérebro humano após diferentes processos de aprendizagem 35 .

Assim, por exemplo, pesquisas revelam mudanças na quantidade de massa cinzenta nas regiões médiotemporal e intraparietal, geradas pelo treino, mostrando sua eficácia na aprendizagem motora [36]. Da mesma forma, estudos com o uso de RMf revelaram que existem pelo menos dois sistemas neurais envolvidos no processamento matemático de informação [22, 37]. Com isso, para Dehaene, resultados deste tipo podem contribuir para a compreensão do aprendizado da Matemática, visto que propiciam uma ferramenta de análise adicional, capaz de ajudar os professores a se posicionarem perante dicotomias típicas da área de Educação Matemática, como o ensino por procedimentos versus ensino de conceitos.

Do mesmo modo, tem se avançado na compreensão sobre o desenvolvimento de sistemas neuronais envolvidos na atenção e no controle cognitivo. Tais resultados podem conduzir, por exemplo, discussões acerca das limitações da aprendizagem, no sentido de revelarem como o desenvolvimento de habilidades aritméticas depende da maturação cerebral, de modo que tais limitações podem deixar de ser atribuídas exclusivamente ao método de ensino ou à falta de aptidão do estudante [38-40]. Outras descobertas revelam que diferentes aspectos da memória são ativados em diferentes contextos emocionais [41 44, possibilitando, assim, aprofundar as discussões acerca das relações entre emoção e cognição. Resultados da neurociência cognitiva também podem contribuir para o entendimento dos papéis do sono e da nutrição no desenvolvimento cerebral e na aprendizagem, fornecendo dados objetivos que podem ajudar os educadores a decidir se e como integrar estas variáveis em seus currículos ou em programas de política de ensino.

Com essa breve panorâmica sobre o que vem sendo realizado na Neurociência nas últimas décadas pode-se 
perceber o quanto se avançou na compreensão mais profunda de inúmeros mecanismos essenciais para a aprendizagem e largamente considerados em pesquisas em Ensino. A partir de uma abordagem completamente diferente, estes achados podem contribuir de maneira inédita para as investigações tradicionalmente feitas na área, levando a um entendimento mais complexo e aprofundado acerca dos condicionantes da aquisição e uso do conhecimento científico. A fim de revelar o potencial destas pesquisas, especificamente, para o Ensino de Física, serão apresentadas de forma detalhada algumas pesquisas icônicas relacionadas ao processamento cerebral da Matemática, elemento determinante na estruturação do pensamento físico [45].

\section{A Matemática no Cérebro}

A cada ano surgem mais pesquisas que investigam a capacidade exclusivamente humana de criar e processar conceitos matemáticos abstratos. Há um campo efervescente de estudos acerca das regiões cerebrais, rede neurais e mecanismos psicológicos que sustentam a capacidade de representar simbolicamente os números e de realizar cálculos matemáticos. Uma das hipóteses mais trabalhadas é que habilidades numéricas préverbais e não simbólicas exibidas por bebês, com poucos meses de vida, e também por animais, servem como base para aprender a contar e adquirir conhecimento matemático simbólico. Chamada de "Teoria do Senso Numérico" foi proposta pela primeira vez por Tobias Dantzig [46], contudo, foi somente a partir dos avanços na neuroimagem que ela ganhou mais aceitação, dadas inúmeras evidências empíricas. Esse "Senso Numérico" pode ser descrito como uma habilidade inata de perceber, manipular e entender pequenas quantidades [47-49] e que essa habilidade, juntamente com outras funções cognitivas e processos educacionais, permite aos humanos compreender e criar princípios matemáticos mais complexos. As evidências revelam a existência desse "Senso Numérico" em bebês a partir de 3 meses, e também em outras espécies animais, como macacos, ratos e pombos, indicando que ele não é adquirido por meio do aprendizado ou da transmissão cultural [49].

Assim, muitos primatas são capazes de, mentalmente, representar quantidades e realizar pequenos cálculo. Pesquisadores mostraram, em uma pesquisa realizada em 1987, que ao oferecerem duas bandejas com pedaços de chocolate a chimpanzés, eles quase sempre escolhem a que tem mais pedaços [50]. Nesse experimento, em uma bandeja eram colocadas duas pilhas de chocolate, uma com 4 pedaços e outra com 3. Havia, ao lado, outra bandeja também com duas pilhas de chocolates, uma com 5 pedaços e outra com 1 pedaço. Sem qualquer treinamento, mais de $90 \%$ das vezes, os macacos escolhiam a primeira bandeja $(4+3)$ em detrimento da segunda $(5+1)$, mesmo com a segunda bandeja contendo uma pilha maior de chocolates, revelando uma capacidade extraordinária de manipulação de quantidades. Esse é apenas um dos mais tradicionais experimentos com matemática e animais, havendo hoje uma vasta literatura no ramo [51, 52].

Bebês em fase pré-verbal, entre 3 e 14 meses, também apresentam habilidades numéricas surpreendentes. Muito semelhante às habilidades dos animais, os bebês nessa idade são capazes de discriminar dois padrões com base apenas na quantidade e podem fazer adições e subtrações simples. Para realizar investigações desta natureza os pesquisadores precisam superar uma dificuldade metodológica importante: um bebê nesta idade ainda não fala, então, como saber se ele reconhece números e faz contas? Um método engenhoso e criativo, chamado de habituação, foi criado por Karmiloff-Smith, em 1992, centrado na atividade mais recorrente na vida de um bebê: olhar atentamente o ambiente. Bebês desta idade perscrutam o seu redor procurando novidades e, essa busca, orienta o seu olhar. Assim, eles olham por mais tempo para as coisas que são novas comparado com as coisas com as quais já se habituaram. Esta metodologia consiste em apresentar, repetidamente, um estímulo ao bebê até que ele perca o interesse e passe a olhar muito pouco tempo para este estímulo. Quando isso acontece, um novo estímulo é apresentado, de modo que se o bebê olhá-lo mais demoradamente pode-se inferir que ele reconheceu que trata-se de um outro estímulo. Nesse processo, a duração do olhar do bebê é medida com muita precisão para se poder concluir que, de fato, esse comportamento aconteceu [53]. Esta mesma metodologia também originou outra técnica chamada de "violação da expectativa" revelando que os bebês tendem a olhar por mais tempo para eventos inesperados, que os surpreendem [54.

Uma pesquisa seminal sobre o senso numérico foi realizada por $\mathrm{Xu}$ e Spelke, em 2000. Ao apresentar para bebês de 6 meses duas imagens contendo diferentes quantidades de pontos, as pesquisadoras encontraram evidências de que eles são capazes de discriminá-los pela quantidade. Usando a metodologia de habituação, os bebês foram expostos repetidamente ao mesmo estímulo, uma tela com 8 ou com 16 pontos. Após se habituarem, eles foram expostos a uma nova tela, com uma quantidade diferente da fase da habituação e, então, eles olharam por mais tempo justamente para a tela com a quantidade numericamente nova, independentemente de terem se habituado com 8 ou 16 pontos. Controlado por diversas outras variáveis, como área total ocupada, densidade dos pontos, luminosidade, cor entre outros, os bebês discriminaram conjuntos de pontos exclusivamente por sua quantidade (Ver Figura 1). A pesquisa revelou que essa habilidade tem seus limites, de modo que os bebês distinguiram facilmente 8 vs. 16 pontos, 16 vs. 32 , mas não 8 vs. 12 ou 16 vs. 24 pontos [55]. Em 2003, Xu desenhou um experimento semelhante para pequenas quantidades, revelando que os bebês conseguiram discriminar 8 vs. 4 pontos, mas falharam com 2 vs. 4 


\section{Habituação}

\section{$1^{\text {a Exposição }}$}
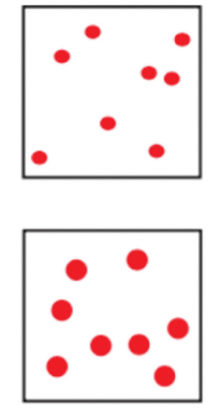

$2^{\mathrm{a}}$ Exposição

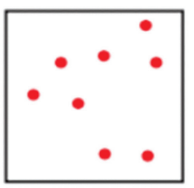

$3^{\mathrm{a}}$ Exposição

etc...
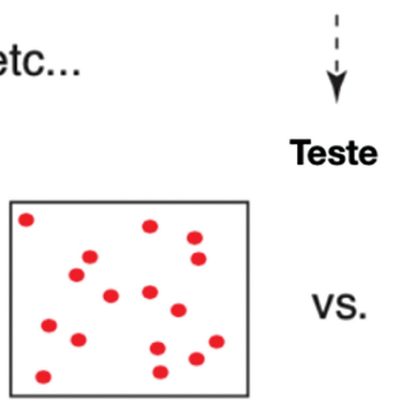

VS.

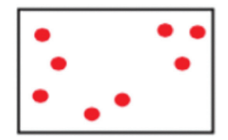

Figura 1: Exemplo de uma tarefa de adaptação de 8 vs. 16 pontos. Adaptado de [47.

ou quantidades menores [56]. Diversas pesquisas foram realizadas desde então, confirmando esses resultados e aprofundando ainda mais a compreensão acerca desse senso numérico inato [57 59].

De maneira geral, as evidências revelam que os bebês muito pequenos, desde 3 meses de idade, precisam pelo menos de uma raza o 1:2 entre as quantidades comparadas para conseguir discriminá-las, mas essa habilidade vai sendo refinada de modo que aos 10 meses já conseguem distinguir 2:3 e, quando adultos 7:8 60]. Além disso, outras pesquisas revelaram que bebês detectam quantidade não apenas em estímulos visuais, mas também em conjuntos de sons e ações, evidenciando que essa capacidade inata de reconhecer quantidades é altamente especializada 61, 62.

A partir destes resultados retirados de pesquisas comportamentais, Izard e colaboradores, em 2008, investigaram os substratos neurais que dão suporte a essa habilidade pré-matemática inata. Para isso, foram geradas imagens de ressonância magnética funcional e EEG de 36 bebês, com idades entre 3 e 4 meses e meio, durante uma tarefa de habituação para pequenas quantidades ( 2 vs. 3 ) e grandes quantidades ( 4 vs. 8 e 4 vs. 12 ) usando como estímulo caras de animais. Assim, os pesquisadores não só variavam a quantidade de objetos, mas também sua identidade. As evidências revelaram que os bebês foram capazes de distinguir as quantidades e os animais, porém usando vias neurais completamente distintas, ou seja, o cérebro infantil respondeu a ambas mudanças, mas engajando diferentes regiões. Mais que isso, a rede parietoprefrontal, ativada nos bebês quando eles estão reconhecendo a quantidade é a mesma que se ativa quando uma criança de 4 anos faz uma tarefa numérica e, quando adulto, faz uma tarefa aritmética complexa. Segundo os autores, essa organização neuronal que dá o suporte à percepção da quantidade e da identidade de um objeto é estabelecida logo no início da vida e aumenta em precisão no curso do desenvolvimento e, possivelmente, permite a criação e aquisição de conceitos matemáticos mais sofisticados [63].

Uma pesquisa icônica, realizada por Wynn, em 1992, que utiliza a metodologia "violação da expectativa", também trouxe evidências acerca de habilidades matemáticas nos primeiros meses de vida. Para isso, foram investigadas 32 bebês, com idades entre 4 e 5 meses. O experimento consistia em apresentar um boneco e, logo em seguida, ocultá-lo por meio de uma tela. Depois, de maneira bem ostensiva, um pesquisador mostrava ao bebê que um segundo boneco está sendo colocado atrás da tela [54]. A hipótese é que quando um boneco está escondido atrás da tela e, em seguida, outro é adicionado, os bebês esperam ver dois objetos $(1+1)$ quando a tela for retirada. A compreensão do bebê foi testada comparando a situação esperada, matematicamente correta, com uma situação inesperada, matematicamente incorreta. Os resultados revelaram que os bebês olharam mais demoradamente quando sua expectativa foi violada, ou seja, eles realmente esperavam ver dois bonecos $(1+1=2)$ do que apenas um ou três bonecos $(1+1=1$ e $1+1=3)$, condição em que olharam por mais tempo. O mesmo ocorreu quando os bebês foram submetidos à subtração, quando existiam dois bonecos atrás da tela e a pesquisadora, então, retirava ostensivamente um deles. Mais uma vez, os bebês olharam por mais tempo quando a conta não batia, ao serem revelados dois ou três bonecos $(2-1=2$ e $2-1=3)$, ao invés de um $(2-1=1)$ (Ver Figura 2).

Estes resultados foram replicados inúmeras vezes, confirmando os achados de Wynn 64. Em 2006, Berger, Tzur e Posner conduziram esse experimento usando, agora, um EEG. Além de confirmarem os resultados de 1992, os pesquisadores encontraram as redes neurais envolvidas na detecção desses erros de aritmética e mostraram que se tratavam das mesmas redes ativadas em adultos, sugerindo que essa habilidade vai se desenvolvendo ao longo da vida 65].

Entretanto, esse "Senso Numérico", essa habilidade inata de representação numérica, é limitada, de modo que não é responsável por processar conceitos matemáticos como frações, raiz quadrada, números negativos ou mesmo números exatos. Isso implica que a construção dos números naturais, racionais e reais depende exclusivamente de processos educativos e 
Sequência de eventos $1+1=1$ ou 2
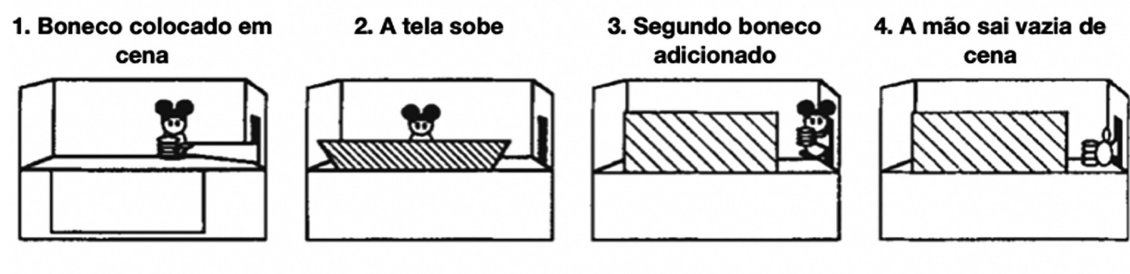

Resultado matematicamente correto

ou

Resultado matematicamente errado

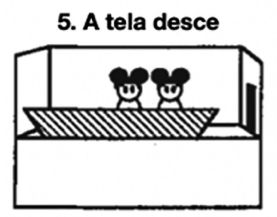

revelando 2 bonecos

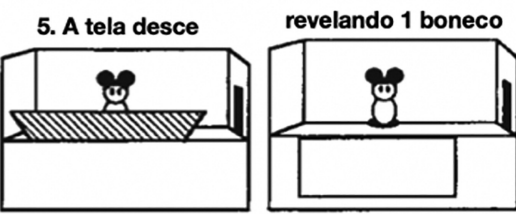

Sequência de eventos 2-1= 1 ou 2

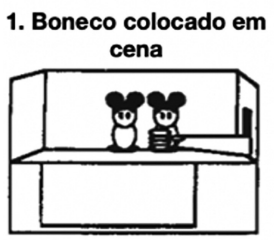

Resultado matematicamente correto

5. A tela desce
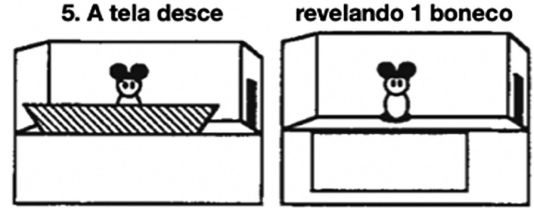

3. Uma mão vazia entra 3 . Um boneco é retirado em cena

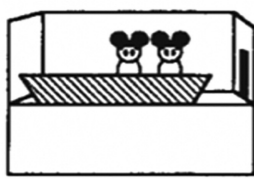

ou
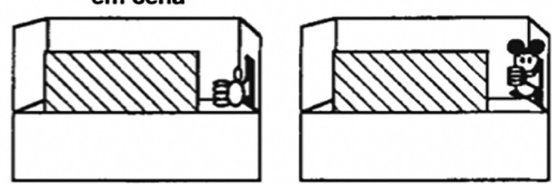

Resultado matematicamente errado

5. A tela desce

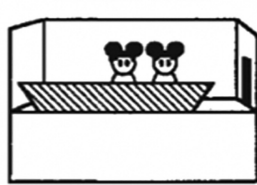

Figura 2: Tarefa de soma e subtração usando a violação de expectativa. Adaptado de [54.

culturais, mas que somente existem por encontrar suporte nesse aparato biológico altamente especializado. Uma pesquisa interessante revela o papel da cultura na forma com que o cérebro processa cálculos matemáticos. Tang e colaboradores, em 2006, revelaram que estudantes nativos no idioma Chinês e nativos na língua inglesa usaram diferentes partes do cérebro para processar os mesmos problemas matemáticos. Resultados de imageamento por ressonância magnética funcional realizados com estudantes na China, Estados Unidos, Austrália, Canadá e Inglaterra, revelaram que, ao resolverem problemas matemáticos, os chineses tinham mais atividade nos centros visual e espacial do cérebro, enquanto os falantes de Inglês tinham mais ativações na rede de linguagem, conhecida como córtex perisilviano. Como esperado, o córtex parietal inferior, engajado no processamento de quantidades numéricas, foi ativado para ambos os grupos, mas o achado mais significativo foi essa distinção funcional entre as redes cerebrais envolvidas no processamento da tarefa. Segundo os autores, a maior ativação de redes que processam o significado das palavras para os nativos em inglês, enquanto nos nativos em Chinês as regiões cerebrais mais ativadas são aquelas que processam a aparência visual e na manipulação física de objetos, deve-se muito mais à cultura e não à linguagem per se 66]. Esses resultados apontam que a codificação biológica diferente para o processamento numérico pode ser moldada pela experiência visual da leitura, durante a aquisição da linguagem e outros fatores como estratégias de aprendizagem e sistemas de ensino, evidenciando a relação indissociável entre cultura e biologia.

Para Dehaene essa habilidade rudimentar para a Matemática, encontrada em bebês e animais é tão fundamental para o cérebro processar e compreender o mundo quanto a capacidade de percepção de cores ou de objetos no espaço. A partir de décadas de investigações, com a compilação de centenas de evidências científicas, foi proposto um modelo chamado de "Modelo de Código Tripld 1]' 49, 67]. Nele, considera-se a existência de três diferentes sistemas de codificação de representações que são recrutados na cognição matemática dependendo da tarefa a ser resolvida. O primeiro sistema, de detecção e processamento de quantidades, seria o "Senso Numérico", que emprega uma representação semântica não verbal de associações de tamanho e distância entre números em uma reta numérica mental. Ele facilita as comparações de magnitude (por exemplo, mais vs.

\footnotetext{
1 Nossa tradução para The Triple-Code Model, visto que o termo não tem uma tradução canônica na área.
} 
menos) e tarefas de aproximação, ou seja, estimativas, e recruta os lados direito e esquerdo do sulco intraparietal, uma estrutura do cérebro associada ao processamento de informações numéricas, entre outras funções cognitivas. O segundo sistema, o sistema verbal, representa os números em um formato verbal, ou seja, léxica, fonológica e sintaticamente. Este sistema é ativado quando processos aritméticos aprendidos por meio do ensino (principalmente o aprendizado mecânico, como as tabuadas) são recuperados na memória. Evidências apontam que este sistema ativa o giro angular esquerdo. E, por fim, o terceiro sistema, o visual, envolvido na representação e manipulação espacial de números em formato simbólico, recrutado em tarefas que exigem orientação da atenção espacial, como na comparação de números, aproximação, subtração e contagem. O lobo parietal superior posterior parece ser o suporte neuronal desse sistema. Este modelo, que tem sido testado ao longo do tempo, é largamente utilizado para investigar diferentes hipóteses sobre a aprendizagem de Matemática e para especular sobre redes neurais que suportam a cognição numérica. Mais que isso, ele orienta teoricamente diversos programas de ensino, que vem sendo usados, e testados em sala de aula, com o objetivo de auxiliar na superação de dificuldades de aprendizagem matemática e para promover o desenvolvimento numérico 68 71 .

Seria importante que a área de pesquisa em Ensino de Física se espelhasse no que vem sendo realizado nos estudos mais recentes sobre a ciência da mente e do cérebro. Longe de ser uma revisão extensa, foram apresentadas até agora algumas pesquisas centrais que mudaram por completo o que se pensava sobre cognição matemática e, mais que isso, criaram uma base teórico-metodológica que fundamenta centenas de outras pesquisas que estão sendo realizadas hoje mesmo. É preciso ressaltar que é graças a um esforço contínuo, centrado em unir Psicologia, Neurociência e Educação que toda essa revolução foi feita na compreensão dos processos de aprendizagem de Matemática, gerando um modelo teórico que integra estas três áreas, oferecendo evidências robustas acerca de suas hipóteses e podendo, assim, orientar práticas pedagógicas também baseadas em evidências. Foge do escopo deste artigo apresentar resultados surpreendentes em investigações sobre linguagem e leitura, mas o avanço nesses campos também tem sido enorme e com um alto potencial para impactar o que sabemos sobre a aprendizagem de conteúdos científicos. Com isso, elementos centrais dos processos cognitivos que permitem a interpretação física do mundo, as redes cerebrais associadas ao aprendizado da matemática, da leitura e da linguagem, estão sendo cada vez mais compreendidos. Contudo, muito pouco tem sido feito com a Física, tema ideal para investigar modelos mentais no cérebro.

Assim, serão apresentadas agora pesquisas que buscaram, especificamente, investigar o processamento de conteúdos da Física no cérebro. Uma vez mais é preciso ressaltar que o objetivo aqui é fazer um convite aos pesquisadores em Ensino de Física a avaliarem o imenso potencial deste tipo de investigação para o tratamento de temas caros à área.

\section{A Física no Cérebro}

Como visto, embora muito se tenha avançado em pesquisas sobre Matemática e linguagem no cérebro, elementos imprescindíveis para a construção do conhecimento físico do mundo, muito pouco se sabe sobre os mecanismos neuronais que dão suporte ao aprendizado de conteúdos da Física. Uma das poucas investigações nesse sentido foi realizada por Mason e Just, em 2015. A pesquisa apresenta evidências das mudanças cerebrais que ocorrem não após, mas durante o processo de aprendizagem. Os pesquisadores usaram imagens de ressonância magnética funcional para investigar os padrões de ativação cerebral enquanto os sujeitos aprendiam conceitos de mecânica a partir de quatro diferentes sistemas: uma balança de banheiro, o freio de um carro, um extintor de incêndio e um trompete. As representações neurais relacionadas à apreensão do funcionamento destes aparatos foram coletadas antes, durante e depois de três fases incrementais de ensino: primeiro foram oferecidas informações sobre os componentes do sistema, depois foram apresentadas as relações causais parciais do funcionamento destes sistemas e, por fim, foram dadas informações completas sobre como eles funcionam. Mais do que buscar encontrar possíveis correspondências entre funções cognitivas e ativações de regiões cerebrais, o objetivo principal dessa investigação foi identificar como um novo conhecimento físico é construído no cérebro ao longo de diferentes estágios de aprendizagem [72].

Por meio de ressonância magnética funcional, foram investigados os cérebros de 14 estudantes da universidade Carnegie Mellon enquanto eles aprendiam, pela primeira vez, sobre estes quatro sistemas mecânicos simples. Havia três tipos diferentes de blocos de ensino do funcionamento dos sistemas. O primeiro tratou-se de uma descrição de seus componentes, que consistia em uma imagem real e seu diagrama esquemático, juntamente com uma frase descrevendo seus componentes. No segundo bloco de explicação foram fornecidas informações causais parciais, introduzindo a primeira metade da sequência causal do funcionamento do sistema. O terceiro e último bloco de explicação apresentou as informações funcionais completas, constituindo uma descrição total do funcionamento do sistema mecânico. Após cada bloco, era pedido aos sujeitos que pensassem sobre o sistema explicado. Os resultados revelaram que depois de cada instrução os padrões de pensamento dos estudantes mudaram. Esta sequência de explicações permitiu aos pesquisadores identificarem as redes neurais ativadas durante cada etapa da aprendizagem, acompanhando como cada novo conceito foi de palavras e imagens para representações neurais. 
As evidências encontradas por Mason e Just (2015) apontam que estas representações neurais progrediram por estágios, espacial e temporalmente distintos, com cada um deles engajando diferentes áreas do cérebro, associadas a diferentes processos cognitivos. Inicialmente, houve uma maior ativação do córtex occipital, indicando que a representação do sistema foi primordialmente visual. Em seguida, nos estágios intermediários, foram ativadas diversas regiões corticais, como a parietal, temporal e frontal medial, associadas a processos cognitivos como inferência causal, linguagem e movimento, redes comumente ativadas quando um sujeito realiza uma animação mental. Isso sugere que os estudantes estavam imaginando o movimento dos componentes mecânicos para inferir como eles interagiam em uma cadeia causal de funcionamento. Por fim, o último estágio apresentou uma forte ativação das regiões frontal e motora do córtex frontal, associadas às funções executivas e à cognição incorporada, sugerindo que os participantes imaginaram como uma pessoa, ou eles mesmos, interagiria com os sistemas. Assim, estes resultados sugerem diferentes mecanismos que compõem a aprendizagem de sistema mecânicos: (1) codificação de informações; (2) animação mental, possivelmente envolvendo imaginar os componentes em movimento; (3) geração de hipóteses causais associadas à animação mental; e (4) determinação de como uma pessoa interage com o sistema (Ver Figura 3).

Além disso, usando aprendizado de máquina, os pesquisadores criaram "classificadores" capazes de identificar o padrão de ativação neuronal para cada um dos quatro sistemas mecânicos, de modo que era possível "adivinhar" em qual deles o estudante estava pensando com base apenas em seus padrões cerebrais. Essa é a primeira pesquisa que permite a criação de uma teoria inicial de aprendizagem de sistemas físicos com base cortical que, potencialmente, pode ser relacionada às teorias cognitivas largamente conhecidas na área de Ensino de Física, sugerindo conexões entre representações neurais, estágios de aprendizagem e a compreensão de conteúdos simples. É importante ressaltar que esta pesquisa mostrou que é factível investigar como cada etapa do processo de ensino deve resultar em mudanças neurais perceptíveis, revelando que podem ser realizadas uma série de investigações acerca da aprendizagem de conteúdos físicos.

Os mesmos autores, Mason e Just, agora em 2016, identificaram padrões da atividade cerebral quando estudantes de Física e Engenharia pensavam em conceitos físicos. Foi a primeira vez que tal resultado foi obtido, identificando e caracterizando redes neurais que dão suporte à representação de conceitos centrais da Física, podendo, ao fim, classificar estes padrões de ativação. Para isso, 9 estudantes da universidade Carnegie Mellon, todos graduados ou fazendo pós-graduação em Física ou Engenharia, foram colocados em uma ressonância magnética e tinham a tarefa de pensar ativamente sobre as propriedades que eles associavam aos conceitos apresentados. Foi certificado que todos eles haviam concluído cursos de Física para além do nível introdutório e tinham boa familiarização com os conceitos usados como estímulos. A lista consistia de: aceleração, força centrípeta, difração, corrente contínua, deslocamento, carga elétrica, corrente elétrica, campo elétrico, energia, entropia, força, frequência, gravidade, transferência de calor, inércia, energia cinética, luz, campo magnético, massa, momentum, energia potencial, ondas de rádio, refração, ondas sonoras, temperatura, energia térmica, torque, velocidade, voltagem e comprimento de onda 73 .

Embora a tarefa não pedisse uma resposta direta, do tipo certo ou errado, ela exigia uma interação orientada a partir das propriedades do conceito. Assim, logo antes de entrarem na ressonância, os estudantes tinham que falar três propriedades para cada um dos termos, como "quantidade vetorial", "movimento relativo" e "direção" para o conceito "velocidade". O objetivo da tarefa era determinar se cada um destes conceitos possui um padrão neural específico, consistente e identificável por meio de um "classificador" gerado a partir da aprendizagem

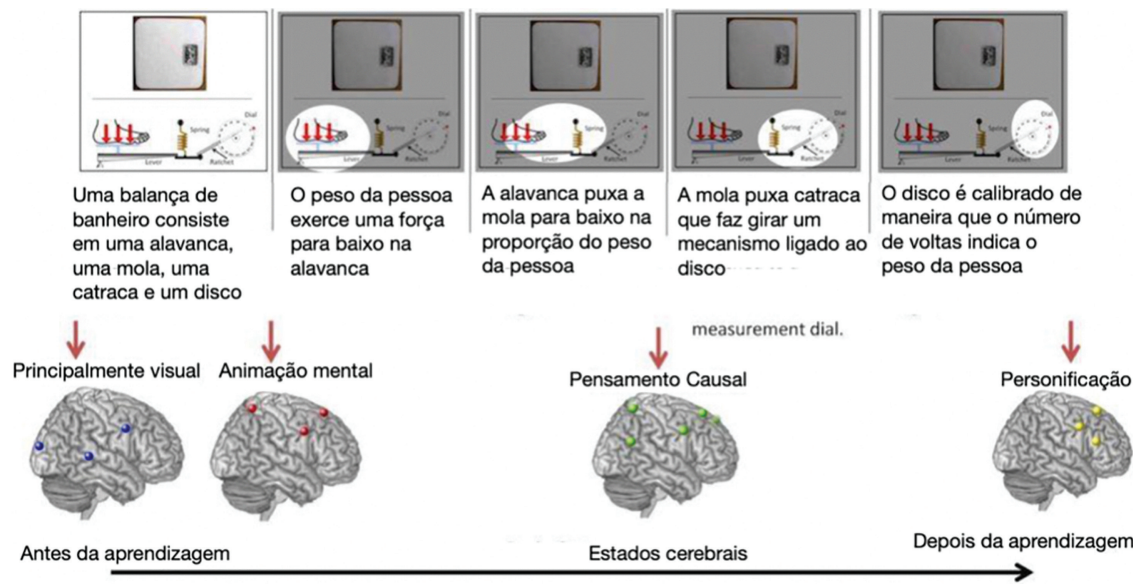

Figura 3: Diferenças na ativação cerebral correlacionadas com diferentes fases de explicação do mecanismo de funcionamento de uma balança de banheiro. Adaptado de [72]. 
de máquina, que buscava reconhecê-lo e aprendê-lo. Dentro da ressonância, cada conceito foi apresentado seis vezes, em ordens completamente aleatórias. Cada palavra aparecia numa tela por um determinado tempo durante o qual os estudantes deveriam refletir sobre o conceito apresentado.

Os pesquisadores, então, identificaram ativações cerebrais bem específicas para cada conceito. Mais que isso, essa atividade cerebral era a mesma em todos os participantes quando estavam pensando no mesmo conceito, ou seja, ao pesarem em "gravidade" todos os estudantes tinham as mesmas regiões do cérebro ativadas, e que eram diferentes de quando pensavam em "campo elétrico". O mais interessante é que os resultados mostraram que estes padrões de ativação neuronal reaproveitavam sistemas neurais já existentes. Conceitos físicos de "frequência" ou "comprimento de onda" ativaram as mesmas regiões que são ativadas quando dançarinos assistem alguém dançar, ou quando alguém ouve música ou qualquer padrão rítmico. Já conceitos como "velocidade" e "aceleração", em geral definidos por meio de equações, ativaram áreas cerebrais envolvidas em processamento aritmético e processamento de sentenças verbais. Esses resultados sugerem que o aprendizado de conceitos físicos é realizado por meio do reaproveitamento de estruturas neurais que são, originalmente, usadas para propósitos gerais do dia a dia. Segundo os autores, o cérebro é capaz de aprender estes 30 conceitos físicos dada a capacidade de processamento e compreensão de quatro conceitos fundamentais, chamados por eles de "classificadores": movimento causal, periodicidade, fluxo de energia e representações algébricas.

I - movimento causal: aqui estão muito dos conceitos pertencentes ao ensino de Mecânica: gravidade, energia potencial, deslocamento, torque e força centrípeta. Ao pensar nesses conceitos, foram ativadas redes neurais da junção occipital-temporal-parietal esquerda, sulco intraparietal esquerdo e giro frontal médio esquerdo, regiões associadas à visualização de objetos em movimento e ao processamento de relações causais.

II - periodicidade: aqui estão conceitos "comprimento de onda", "ondas de rádio", "frequência", "difração" e "ondas sonoras". As localizações cerebrais que dão suporte a estes conceitos incluíram giro parietal superior bilateral, sulco pós-central esquerdo, giro frontal superior posterior esquerdo e giro temporal inferior bilateral, regiões fortemente associadas à percepção de qualquer fenômeno periódico e eventos temporalmente regulares. Algumas dessas regiões estão no córtex somatosensorial, sugerindo que exista uma "incorporação" desses conceitos, de modo que as sensações destes movimentos periódicos podem ser simuladas no corpo.

III - fluxo de energia: tem-se aqui os conceitos de "campo elétrico", "luz", "corrente contínua", "ondas sonoras" e "transferência de calor", termos presentes no ensino de Eletricidade e Termodinâmica. Foram ativados o sulco intraparietal esquerdo, sulco pré-central esquerdo, giro temporal médio posterior esquerdo e giro frontal inferior, regiões envolvidas na associação semântica entre conceitos abstratos e a visualização de objetos concretos, bem como em áreas da linguagem responsável por decodificar conceitos abstratos. Esse "classificador" foi criado a partir das propriedades apresentadas pelos estudantes quando eles as associavam a cada um dos conceitos. Para o conceito de "corrente contínua", por exemplo, vários participantes relataram propriedades como "fluxo" ou "fluxo de elétrons". Para "transferência de calor" surgiu "radiação", e para "campo elétrico" foram citadas propriedades como "radial a partir de uma carga pontual". Os autores consideraram que tais conceitos possuem uma ontologia comum e que o mais alto nível de abstração que engloba todos esses conceitos é o fluxo de energia.

IV - representações algébricas: aqui estão os conceitos como "velocidade", "aceleração" e "transferência de calor", todos os quais, particularmente, definidos e fortemente associados a equações bastante familiares. Foram ativadas a região pré-cuneiforme, no lobo parietal esquerdo, no giro frontal inferior esquerdo e no giro occipital esquerdo, áreas normalmente envolvidas no processamento algébrico e aritmético. Os autores ressaltam que ainda que muitos conceitos da Física têm forte associação com equações, algumas são mais conhecidas que outras, de modo que a fórmula da velocidade é muito mais familiar que a fórmula da difração. $\mathrm{O}$ interessante aqui é notar que regiões cerebrais envolvidas em cálculos matemáticos estão sendo ativadas mesmo que eles não estejam sendo, de fato, realizados naquele momento, revelando uma importante forma que o conhecimento fica codificado no cérebro. Esse "classificador" surgiu a partir de formulações algébricas relatadas pelos estudantes como propriedades dos conceitos. À "velocidade", por exemplo, foi associada " $\mathrm{dx} / \mathrm{dt}$ ", para "transferência de calor" vários estudantes citaram a constante de Boltzmann, e "corrente elétrica" suscitou a lei de Ohm como propriedade. (Ver Figura 4).

As descobertas de Mason e Just (2016) fornecem uma inédita visão da aprendizagem de vários conceitos fundamentais da Física, com suas representações identificadas agora em termos de organização cerebral. O importante a ser discutido é que tais conceitos são altamente abstratos e aprendidos exclusivamente por meio dos processos educacionais. Para os autores "existe um caminho comum que vai das capacidades básicas do cérebro humano até aos conceitos abstratos da física, desenvolvido apenas nos últimos séculos e exclusivamente ensinados por meio da escolaridade formal" ([73] pg 7, tradução nossa). Mais que isso, esses conceitos, para serem apreendidos, se utilizam de redes neurais altamente especializadas, talhadas por milhões de anos no processo evolutivo para serem usadas com precisão na vida cotidiana, evidenciando mais uma vez a indissociabilidade entre Educação e aparato biológico. 


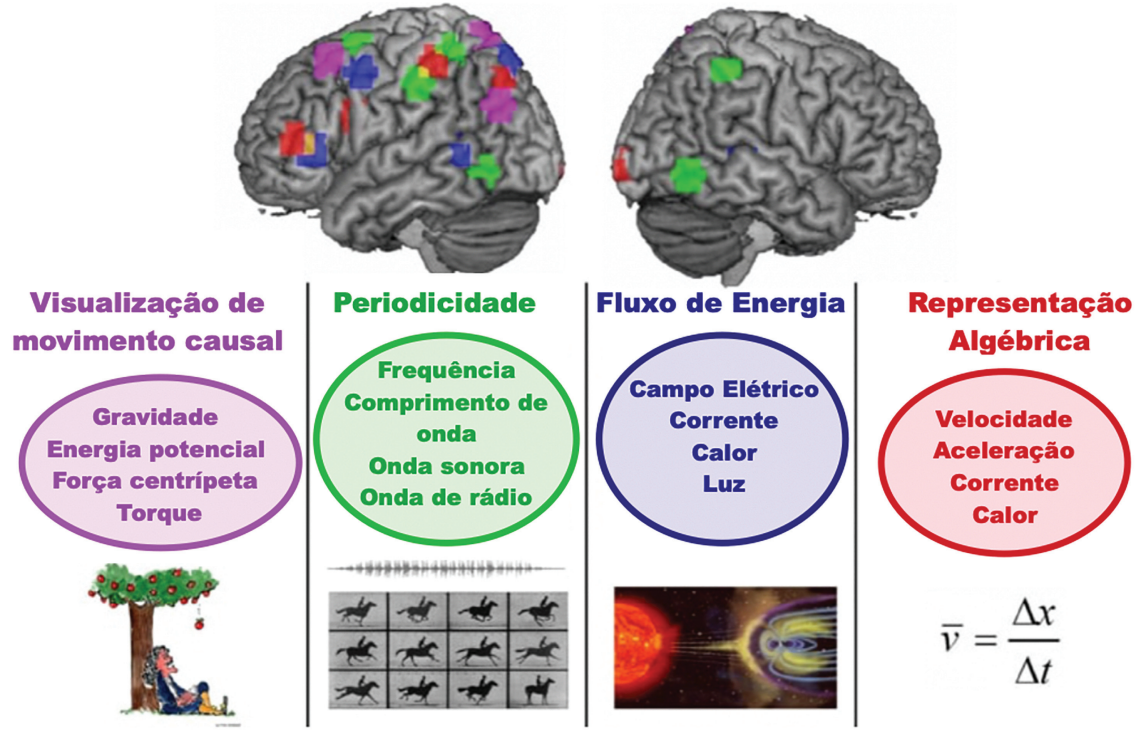

Figura 4: As diferentes regiões cerebrais ativadas para um dos 4 grandes grupos de conceitos de Física. Adaptado de [73].

Seguindo nos estudos com imageamento cerebral, destaca-se também o trabalho de Brewe e colaboradores, em 2018. Os autores usaram ressonância magnética funcional para investigar possíveis mudanças neuronais induzidas por uma determinada prática de aprendizagem ativa chamada "Modeling Instruction" 74]. Desenvolvida por Brewe (2008), trata-se de uma abordagem pedagógica que se fundamenta em uma característica específica da epistemologia científica, a modelagem [75]. Um curso de Mecânica foi montado a partir da integração entre componentes de laboratório de física com exposição de conteúdo, em aulas com formato de estúdio, nas quais os estudantes tinham flexibilidade para se engajarem em diferentes atividades, como resolução de problemas, discussões conceituais ou experimentação. O objetivo era o desenvolvimento e a testagem de modelos qualitativos e quantitativos dos fenômenos físicos. O artigo apresenta, em seu início, uma visão geral desta abordagem, discutindo suas bases teóricas, seu desenvolvimento e recursos principais para, em seguida, descrever a pesquisa e seus resultados.

Participaram do estudo 55 estudantes da Universidade da Flórida que ainda não tinham feito nenhum curso de Física em nível universitário. Todos eles tiveram seus cérebros escaneados enquanto respondiam a questões do Force Concept Inventory (FCI) antes e depois de passarem pelo "Modeling Instruction". O FCI é um questionário de conteúdos de Mecânica largamente conhecido e pesquisado no Ensino de Física [76]. Centradas em cenários mais cotidianos, as perguntas do FCI não requerem nenhum cálculo matemático e são apresentadas a partir de um texto que descreve o cenário acompanhado por um diagrama representacional. Os estudantes também responderam a uma série de questões de controle, que tinham características semelhantes às questões do FCI em termos de requisitos de leitura, complexidade visual e design, contudo, sem qualquer relação com a Física. Essas eram questões que focavam na compreensão da leitura e na discriminação de formas geométricas, de modo a ser possível isolar os processos cognitivos relacionados ao raciocínio físico ao contrastar os padrões neuronais ativados quando eram respondidos os dois tipos de perguntas, as do FCI e as de controle.

É preciso ressaltar, então, que esta pesquisa foi a primeira a tentar entender não apenas as bases neurais que dão suporte ao raciocínio da Física, mas também investigar quais as mudanças na atividade cerebral são geradas por uma determinada abordagem pedagógica. Quando se analisa os resultados relacionados às respostas das questões (FCI vs. Controle), houve a ativação de diversas porções de quatro áreas cerebrais diferentes: o córtex pré-frontal, o córtex parietal, os lobos temporais e o cerebelo direito. Tais regiões, são largamente conhecidas por darem suporte a processos cognitivos essenciais para raciocínio físico, como atenção, memória de trabalho, pensamento espacial e cognição matemática. Esses mesmos padrões de atividade cerebral também foram observados no pós-teste, meses depois do préteste, mostrando haver uma consistência na forma que o cérebro processa o pensamento de conteúdos da Física e, segundo os autores, esses resultados não devem depender da abordagem pedagógica utilizada sendo, assim, uma rede neural que suporta a construção do conhecimento físico do mundo.

Ao se analisar os resultados relacionados aos impactos da forma de ensino, o "Modeling Instruction", após o curso identificou-se a ativação dos lobos frontais, córtex cingulado posterior, córtex pré-frontal dorsolateral e giro angulado. Essas regiões cerebrais são associadas a processos cognitivos internamente orientados, como auto-reflexão, divagação, memória autobiográfica e planejamento. Elas também estão envolvidas na resolução 

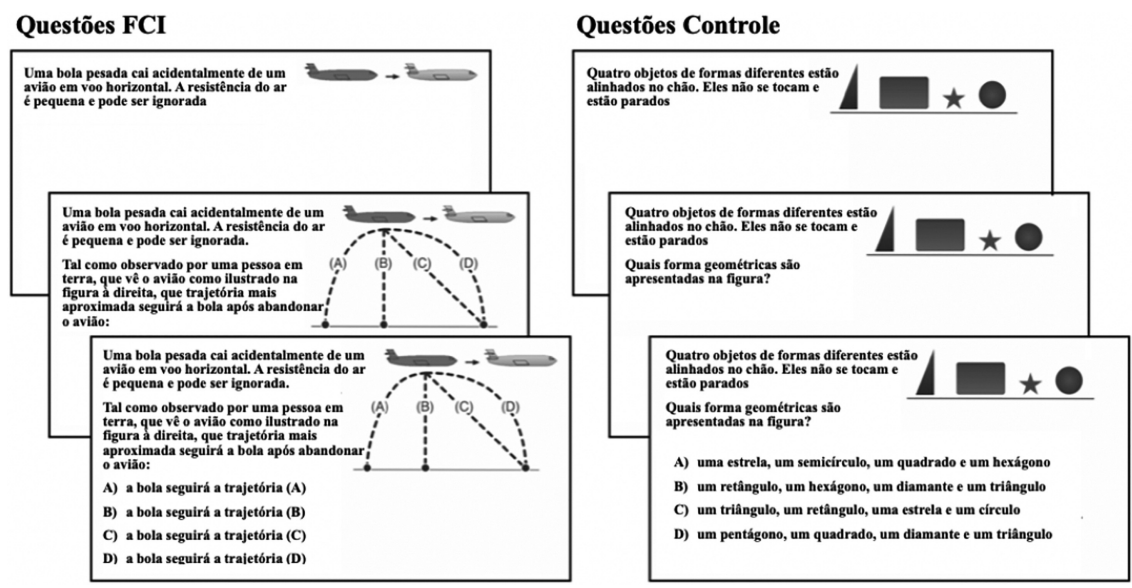

Figura 5: Exemplos de questões e da forma de apresentação em três fases. Adaptado de [77].

de tarefas complexas, compreensão de narrativas, processamento semântico e na geração e manipulação de imagens mentais. Chama atenção a ativação do córtex pré-frontal dorsolateral, apenas no pós-teste, depois te terem concluído o curso. Essa é uma região associada à produção de simulações mentais, sugerindo que os estudantes criam imagens mentais para simular eventos e formular previsões. Segundo os autores, a ativação desta região em específico se deve à abordagem pedagógica. Ainda que não seja possível afirmar com certeza, visto que não a contrastaram com outra abordagem, é importante reconhecer a ativação de uma rede neural associada à simulação e produção de imagens mentais após uma forma de ensino que incentiva os alunos a usarem seus próprios modelos mentais para compreender novos conceitos.

Em outra pesquisa realizada na Universidade da Flórida, em 2019, Bartley e colaboradores também usaram de neuroimagem para entender as estratégias que os estudantes usam para resolver problemas conceituais e como isso impacta na aprendizagem [77. Foram investigados 107 alunos de graduação que haviam concluído um semestre de um curso introdutório de Física. Atividade cerebral dos estudantes foi coletada também enquanto eles resolviam questões do FCI e, como controle, questões que focavam na compreensão da leitura e na discriminação de formas geométricas. As questões de Física e as de controle foram apresentadas em três fases: I - Iniciação do problema, na qual os estudantes visualizavam um texto e uma figura descrevendo um cenário físico; II - Apresentação $\boldsymbol{d a}$ pergunta, na qual os estudantes viam uma questão de física sobre o cenário e III - Seleção de resposta, em que quatro opções de resposta possíveis eram exibidas para a escolha do sujeito. (Ver Figura 5).

Tal desenho experimental permitiu identificar as redes neurais ativadas enquanto os alunos completavam etapas sucessivas da resolução destes problemas conceituais e avaliar como suas respostas se relacionavam a esses diferentes padrões de ativação cerebral, explorando correlações entre esses substratos neurais e o desempenho, a dificuldade, a estratégia e a conceituação acerca das ideias da Física. É preciso ressaltar que os estudantes acertaram cerca de $62 \%$ das respostas do FCI, resultado já esperado devido à presença das concepções alternativas, e $99 \%$ das questões controle, revelando que a tarefa foi adequada ao que se desejava investigar.

Inicialmente, os resultados revelaram que as mesmas regiões cerebrais foram ativadas em todos os estudantes quando eles estavam resolvendo as questões de Física. Então, comparadas com a ativação das questões de controle, houve a ativação de uma rede frontotemporoparietal, incluindo o córtex pré-frontal, o estriado dorsal esquerdo, o córtex parietal posterior, o córtex cingulado posterior dorsal, o córtex occipitotemporal lateral e o cerebelo. Essa miríade de áreas é conhecida como "rede executiva central2', visto que é uma rede neuronal associada a diferentes funções cognitivas, como raciocínio lógico, tomada de decisão, atenção, aprendizagem e memória. Para que fosse possível compreender melhor a relação entre as ativações neuronais e o processo mental de criação das respostas às questões de Física, os pesquisadores, então, analisaram as ativações correspondentes a cada uma das três fases de resolução dos problemas. A fase I ativou regiões ligadas à atenção visuoespacial, à percepção, ao controle motor e à memória. Já a fase II engajou regiões associada à memória de curto prazo e cognição numérica, enquanto a fase III ativou regiões que dão suporte à mentalização, à exploração mental de uma solução. Segundos os autores, esses resultados revelam que o pensamento físico se dá a partir da cooperação e interação entre todas essas áreas (Ver Figura 67.

Após essa etapa, os pesquisadores analisaram se havia alguma diferença na ativação cerebral relacionada ao desempenho dos estudantes, ou seja, se havia alguma distinção na ativação neuronal quando o aluno respondia de forma correta ou incorreta. Os resultados revelaram

\footnotetext{
${ }^{2}$ Nossa tradução para Central Executive Network.
} 


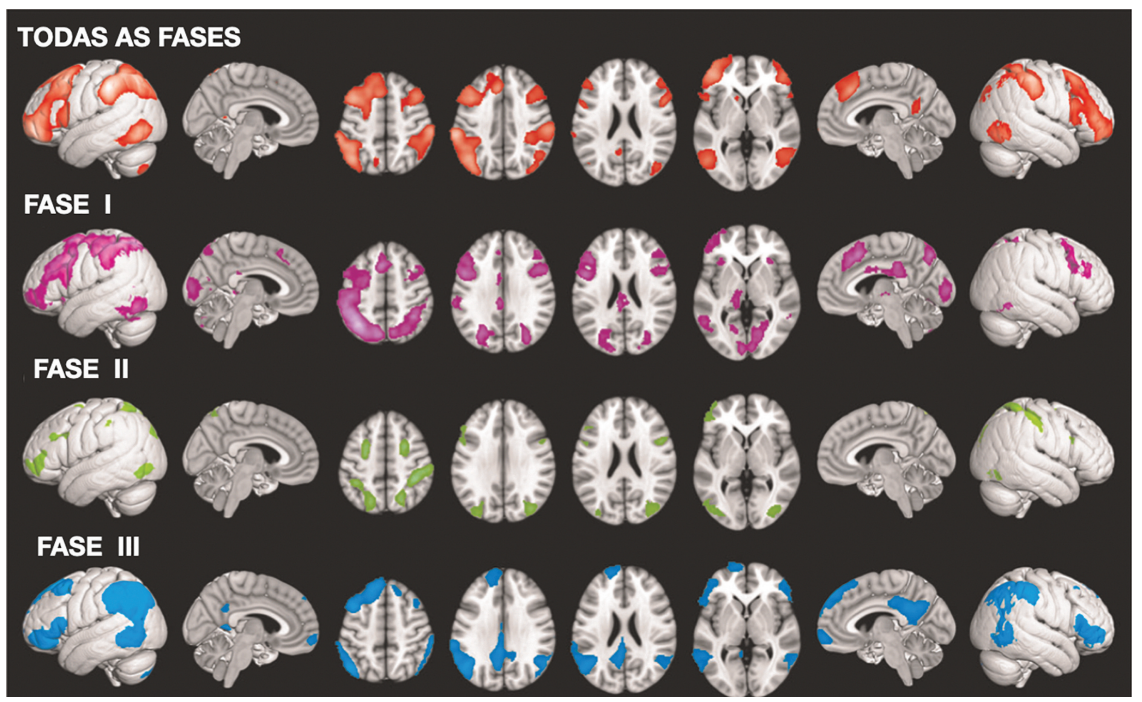

Figura 6: Imagens de ressonância magnética funcional evidenciando as diferentes regiões cerebrais ativadas em cada uma das fases de aprendizado. Adaptado de [77].

que não houve qualquer diferença na atividade cerebral associada a responder certo ou errado. Em outras palavras, a rede neural que suporta o raciocínio físico foi ativada de maneira consistente, independentemente de o estudante pensar em uma resposta fisicamente correta ou em uma concepção alternativa. A partir desse resultado, os pesquisadores usaram um algoritmo de detecção nas distribuições de respostas para identificar subgrupos de alunos que responderam de modo semelhante às questões do FCI. Três grupos, A, B e C, foram formados com estudantes que acertaram, respectivamente, $78 \%, 73 \%$ e $53 \%$ das respostas. Depois, foram comparadas as atividades cerebrais entre os grupos, revelando importantes resultados. Primeiro, os estudantes dos grupos A e B, que apresentaram mais ideias corretas sobre a Física, mesmo quando erravam, apresentavam forte ativação da "rede executiva central", sugerindo que eles viam uma coerência lógica interna nestas concepções espontâneas. Já os estudantes do grupo C engajaram áreas do cérebro mais associadas à visão, à detecção de informações do mundo externo e à memória pessoal, sugerindo que aqueles que não tinham certeza sobre os conteúdos de Física passaram mais tempo buscando pistas que julgaram importantes de um problema, estavam mais apoiados na lembrança de suas próprias experiência e, com isso, gastaram menos tempo realmente raciocinando para encontrar uma solução.

Nesse mesmo caminho, uma pesquisa interessante realizada com estudantes de universidades do Canadá trouxe evidências importantes para a compreensão de um problema antigo na área de Ensino de Física: a persistência das concepções alternativas. Talvez um dos temas mais escrutinados no Ensino de Ciências seja a "mudança conceitual". Inúmeros pesquisadores se debruçam sobre o tema desde a década de 70 , sem que haja um consenso acerca de seus mecanismos, e diversos modelos foram, então, elaborados. Um dos mais conhecidos descrevem a mudança conceitual como uma espécie de "acomodação" na qual os conceitos espontâneos são "substituídos" pela estrutura científica ou substancialmente reorganizados. Mas, de modo geral, duas hipóteses principais ainda permanecem sem confirmação pela comunidade de Ensino: as concepções alternativas são totalmente transformadas ou substituídas pelas científicas, desaparecendo por completo do quadro explicativo dos estudantes após uma mudança conceitual ou estas concepções espontâneas ainda ficam presentes na mente do estudante, mesmo após uma mudança conceitual, coexistindo com os novos conhecimentos científicos? Foisy e colaboradores (2015) investigaram o que ocorre no cérebro quando um aluno precisa responder qual bola chega primeiro ao chão, a mais leve ou a mais pesada 78. Essa concepção espontânea foi especialmente escolhida, a partir da análise de inúmeros trabalhos no tema, por se mostrar a mais persistente das várias que existem em Mecânica. Para isso, eles recrutaram 29 estudantes de uma universidade de Montreal. Os sujeitos foram divididos em dois grupos: Experts e Novatos. O primeiro grupo era composto de estudantes de bacharelado em Física e que haviam feito aulas opcionais de Ciências durante o Ensino Médio. Já o grupo dos Novatos era formado por estudantes de bacharelado em cursos das Humanidades, como História, Psicologia, Política, Filosofia e Administração, e que nunca haviam feito aulas opcionais de Ciências, recebendo, assim, uma educação científica básica do sistema escolar daquele país.

Para a coleta das imagens cerebrais, todos os sujeitos foram expostos a três tipos de estímulos: filmes não científicos, que não seguiam as leis da Física; filmes científicos, que seguiam corretamente as leis de Newton; e filmes de controle, que não envolviam concepções 
alternativas. Todos eles envolviam bolas caindo. Os participantes deveriam, então, responder se cada filme era correto ou não do ponto de vista científico. Os resultados revelaram diferenças significativas na ativação neuronal de Experts e Novatos quando eles avaliavam os filmes com a concepção espontânea, sugerindo que estes estudantes executaram processos cognitivos distintos. Como esperado, deferentemente dos Experts, a maior parte dos Novatos respondeu como correto os filmes não científicos, com uma bola mais pesada caindo mais rápido que a mais leve. Ao se analisar as respostas cerebrais, os Experts tiveram uma ativação muito maior que os Novatos para duas regiões: o córtex pré-frontal ventrolateral e o córtex pré-frontal dorsolateral, duas áreas associadas ao controle inibitório. Esta ativação foi maior nesse grupo apenas quando julgavam os filmes com concepções alternativas, sendo diminuída tanto para os filmes cientificamente corretos como para os de controle. Segundo os autores, esses resultados revelam que a inibição pode desempenhar um papel fundamental na aprendizagem de Ciências, sugerindo que as concepções espontâneas dos Experts não foram erradicadas ou transformadas durante a aprendizagem, permanecendo codificadas em suas redes neurais e sendo "apenas" inibidas para fornecer a resposta cientificamente correta.

Um resultado surpreendente diz respeito à ativação do córtex cingulado anterior, área fortemente associado à detecção de erros. Segundo os autores, eles tinham a hipótese que os Experts teriam maior atividade nessa região do que os Novatos, visto que eles sabem que as concepções espontâneas estão erradas. Contudo, não foi o que aconteceu, não houve diferença na intensidade de ativação desta rede entre os grupos. Mais que isso, Novatos apresentaram maior ativação dessa área quando viam os filmes com concepções espontâneas comparado com os fisicamente corretos. Para compreender melhor esse achado é preciso entender o papel do córtex cingulado anterior. Essa região do cérebro é responsável por enviar um sinal ao córtex pré-frontal quando uma situação apresenta um conflito cognitivo. No córtex pré-frontal existem as redes neurais que dão suporte ao controle cognitivo responsável por resolver o conflito, ativando a inibição. Assim, a explicação dada pelos autores para esse resultado é que os Novatos também vivenciaram o conflito cognitivo, mas não foram capazes de inibi-los, ou seja, ainda que seus cérebros tenham detectado o erro eles não foram capazes de resolvê-lo.

Quando se analisa as atividades cerebrais dos estudantes dos dois grupos respondendo de maneira cientificamente correta, verificou-se praticamente a mesma ativação nas áreas pré-frontais em todos os participantes. Para Folsey et al. (2015) estes resultados revelam que a única diferença cerebral significativa entre os grupos é que os Experts tiveram mais ativadas redes neurais associadas ao controle inibitório quando viam aos filmes com concepções alternativas. Para os autores, isso sugere que mesmo após terem se especializado em Física duas redes neurais coexistem, sendo uma relacionada à concepção científica e outra à concepção espontânea. Assim, sendo provável que os Experts não tenham abandonado sua concepção equivocada, mas sim aprendido a inibila ativamente para responder de maneira fisicamente correta.

Como último exemplo do uso de neuroimagem em pesquisas com Ensino de Física, outro estudo interessante investiga outro tema pouco explorado na área, a ansiedade gerada por conteúdos científicos e matemáticos (chamados de STEM [3] [9] Gonzales e colaboradores (2019) investigaram os cérebros de 101 estudantes na Universidade da Flórida, 55 homens e 46 mulheres, que concluíram um curso introdutório de Física necessário para aqueles que pretendem fazer uma graduação na área de exatas, em cursos como Química, Física, Engenharia ou Matemática. Os participantes preencheram uma série de instrumentos de avaliação de ansiedade, tanto clínica como sobre STEM, e realizaram algumas tarefas comportamentais dentro da ressonância magnética, antes e depois do curso. Os resultados revelaram um aumento significativo nos níveis de ansiedade em todos os estudantes, mas houve diferenças significativas entre os sexos, com as mulheres apresentando os níveis mais elevados. Antes de apresentar os dados da neuroimagem é preciso ressaltar que não houve diferenças significativas no desempenho entre mulheres e homens, corroborando com estudos que apontam a existência de estereótipos persistentes que afirmam que os homens têm uma aptidão inata para as disciplinas de STEM.

O maior diferencial desta pesquisa foi usar um modelo bastante conhecido em pesquisas clínicas sobre desordens psicológicas para tentar estabelecer os correlatos neurais da ansiedade relacionada à STEM. Neste modelo investiga-se não somente áreas cerebrais, mas a conectividade entre redes neurais. Inúmeras pesquisas revelam que diversos processos psicopatológicos estão associados ao funcionamento de três redes principais: a "rede de saliêncid4", que encontra suporte no cingulado anterior dorsal e no córtex frontoinsular, responsável por detectar informações salientes no ambiente e focar a atenção; a "rede de modo padrãd5', composta pelo cíngulo posterior e córtex pré-frontal medial, e está envolvida em processos autorreferenciais e normalmente fica desativada durante tarefas cognitivas orientadas por estímulos; e a "rede executiva centra] 6 ", com os córtices dorsolateral pré-frontal e lateral posterior parietal, associada com processos cognitivos como memória de trabalho, resolução de problemas e comportamento direcionado. São as interações dessas três redes que dão origem ao modelo de uma rede tripartite unificadora que tem, em seu mal funcionamento, implicações determinantes nos transtornos psiquiátricos.

\footnotetext{
3 Sigla em inglês para Science, Technology, Engineering and Mathematics.

4 Nossa tradução para Salient Network.

5 Nossa tradução para Default Mode Network.

6 Nossa tradução para Central Executive Network.
} 
Os resultados da pesquisa de Gonzales et al. (2019) revelaram diferenças surpreendentes, entre homens e mulheres, na conectividade destas redes. Os estudantes do sexo masculino exibiram correlações positivas entre conectividade e ansiedade para STEM tanto antes quando depois do curso, e uma correlação negativa entre ansiedade clínica e a conectividade entre a "rede de saliência" e a "rede executiva central" antes do curso. Segundo os autores, estes resultados sugerem alteração nesta rede tripartite relacionada à ansiedade, e há uma importância relevante para a aprendizagem de STEM suprimir interações autorreferenciais, relacionadas à "rede de modo padrão" para que exista um equilíbrio saudável entre as redes. Para corroborar essa hipótese, ao se analisar o desempenho no curso, encontrou-se uma correlação negativa entre a conectividade da "rede de modo padrão" com a "rede de saliência" e a nota dos homens, sugerindo a importância de desligar o processamento interno quando eventos salientes são detectados no contexto da aprendizagem de conteúdos científicos. De modo geral, os dados da ressonância mostraram menos correlações entre a ansiedade clínica pré e pós curso nos alunos do sexo masculino, apesar do aumento da ansiedade para STEM. Para os pesquisadores isso sugere que o cérebro dos homens enfrenta os desafios de seu primeiro curso universitário de Física acomodando o aumento da ansiedade para STEM e equilibrando a resposta a estes desafios.

Já as mulheres, diferentemente, não exibiram correlações significativas entre conectividade e ansiedade nem antes nem depois do curso. Segundo os autores, este resultado sugere a ansiedade para STEM relativamente maior para as estudantes do sexo feminino não impede processos executivos centrais, visto que mesmo mais ansiosas elas tiveram desempenho igual ao dos homens. A hipótese dos pesquisadores para esse achado é que estudantes do sexo feminino podem experimentar ansiedade com os desafios dos cursos de STEM desde o ensino fundamental que, então, podem desencadear ansiedade desde a pré-escola ... Assim, o cérebro das mulheres já se adaptou à ansiedade para STEM. O artigo termina com os autores indicando a importância de se abordar as questões de clima emocional em sala de aula para diminuir a ansiedade para as disciplinas de STEM desde os ensinos fundamental e médio.

As investigações que se apoiam nos arcabouços teórico e metodológico da Neurociência não se resumem na produção de imagens do cérebro. Outro instrumento potencialmente interessante para pesquisas em ensino é o eye-tracker. Trata-se de um aparelho, que capta o reflexo de feixes de luz próximos ao infravermelho nos olhos. Isso permite o rastreamento ocular podendo-se, assim, detectar onde o sujeito coloca sua atenção e foco, bem como a posição de seus olhos e o tamanho da pupila (Ver Figura 7).

É uma técnica não invasiva e que permite uma série de investigações importantes acerca dos processos de

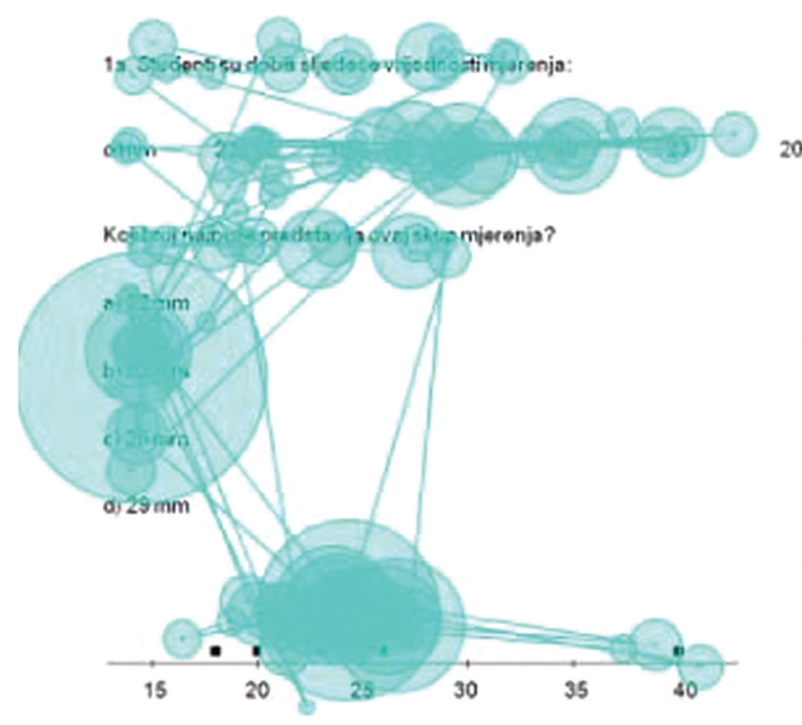

Figura 7: Exemplo de traçado de movimento ocular realizado por um estudante lendo uma questão de Física, obtido por um eye-tracker. Adaptado de [80].

aprendizagem. Como exemplo, Susac e colaboradores (2017) estudaram a influência da representação gráfica dos dados na compreensão e interpretação dos resultados das medições realizadas por estudantes em aulas de laboratório de Física [80]. Participaram da pesquisam 101 alunos de graduação em Física da Universidade de Zagreb, na Croácia. Inicialmente, dividiram esses estudantes em dois grupos e os colocaram para responderem um teste de múltipla escolha sobre incertezas no processo de medição. O teste curto tratava de habilidades de medição básicas como o tratamento dos pontos fora da curva, a comparação entre duas medidas, a distinção entre acurácia e precisão e, por fim, como relatar resultados das medições. Ainda que fosse um teste de múltipla escolha, os estudantes tinham que justificar o porquê da escolha de uma determinada resposta. Um dos grupos recebeu o teste cujos itens incluíam representações gráficas dos dados medidos, enquanto o outro grupo recebeu o teste com os mesmos itens, contudo, sem as representações gráficas. Os resultados revelaram um desempenho melhor no teste para os estudantes que tiveram as representações gráficas disponibilizadas. Após essa etapa, foram então coletados movimentos oculares de uma amostra de 30 outros alunos de graduação em Física da mesma instituição, também divididos em dois grupos e respondendo ao mesmo teste. Os resultados obtidos inicialmente foram confirmados, revelando que os estudantes que receberam as representações gráficas obtiveram pontuação maior do que aqueles que receberam os itens sem as representações gráficas. A análise do eye-tracking permitiu interpretar esse resultado de uma forma mais profunda, apontando uma possível explicação. Os dados revelaram que o tempo total de visualização, ou seja, o tempo gasto na resolução das questões com ou sem representação gráfica, foi o mesmo 


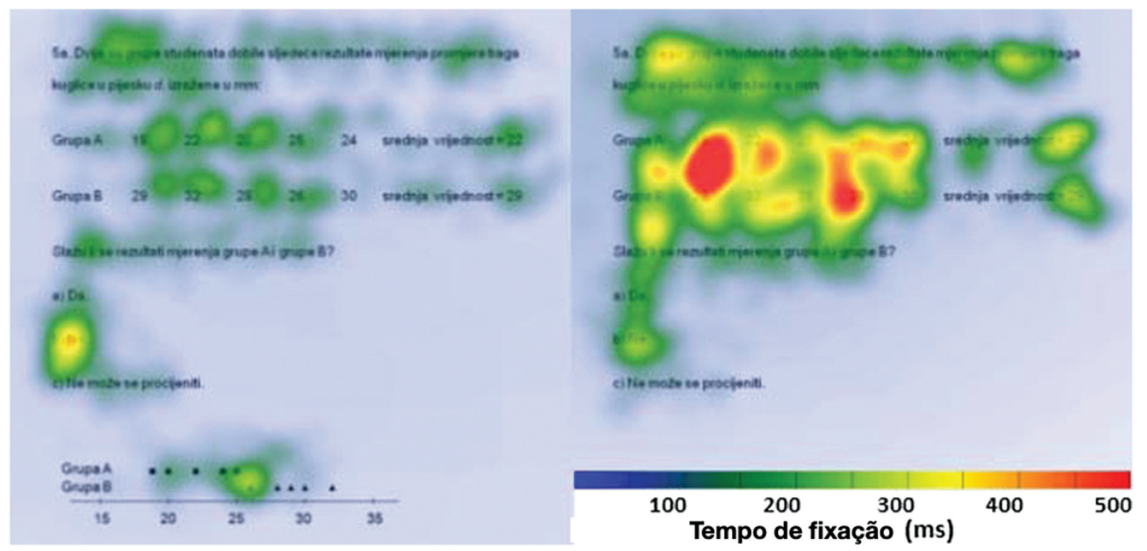

Figura 8: Mapa de calor evidenciando as partes da questão nas quais o aluno olhou por mais tempo, obtido por um eye-tracker. Adaptado de [80].

para os dois grupos de estudantes. Entretanto, os estudantes com os itens que traziam a representação gráfica gastaram muito menos tempo visualizando os dados numéricos. Isso sugere que as representações ajudaram estes estudantes a entender melhor os dados, de modo que eles não precisaram ficar "voltando" aos dados pra responder à questão, diferentemente dos integrantes do outro grupo (Ver Figura 8).

Segundo os autores, esses resultados indicam que a representação gráfica pode ser benéfica para processamento e comparação de dados e comparação de dados, ajudando na visualização e análise das medidas, portanto, os professores devem incentivar os alunos a usá-las.

Esse mesmo grupo de pesquisa fez uso do eye-tracking para investigar o impacto dos diagramas que, tradicionalmente, estão presentes nas questões de Física. O objetivo era verificar se, de fato, eles contribuem para a compreensão do estudante, auxiliando na resolução do problema. Para isso, foram recrutados 60 estudantes de graduação em Física da Universidade de Zagreb. Divididos em dois grupos, os participantes responderam a um teste com 6 questões de múltipla escolha, três delas com diagramas e três sem, alternadas entre os grupos. Os resultados do desempenho revelaram que os diagramas apresentam um pequeno efeito positivo na resolução dos problemas, raramente com significância estatística. Já a análise dos dados de rastreamento ocular sugere que os alunos dividiram sua atenção entre o diagrama e o texto sem acelerar a resolução de problemas, ou seja, os estudantes gastaram menos tempo lendo o texto do problema quando havia um diagrama, mas o tempo total de visualização foi o mesmo para a condição sem diagrama. Segundo os autores, a compreensão da situação física não leva, necessariamente, a uma solução mais eficaz. Ainda que os diagramas possam ser úteis na fase inicial de visualização do problema, eles não garantem a elaboração de uma resposta mais correta.

Utilizando o eye-tracking juntamente com o fNIRS (sigla em inglês para Functional Near Infrared
Spectroscopy) realizamos pela primeira vez um teste de conceito coletando os dados de um aluno na simulação de uma aula real de Física. O fNIRS é um equipamento que usa a luz próxima ao infravermelho para estudar as mudanças nas concentrações relativas de hemoglobina oxigenada ( $\mathrm{HbO})$ e hemoglobina desoxigenada (HbR). A identificação de uma resposta neural, representando a atividade de uma determinada área do cérebro, é baseada no acoplamento neurovascular e é reconhecida como uma resposta hemodinâmica. Tem-se assim, um sinal capaz de revelar as ativações funcionais do cérebro, semelhante ao que é feito na ressonância magnética, bastando apenas que o sujeito use uma touca. Parecida com uma touca de natação, ela contém pares de fontes de luz e detectores que ficam em contato com o couro cabeludo. A luz atravessa a parede craniana, percorrendo um caminho elíptico, até ser recebida pelo fotodetector colocado nas proximidades. Essa da facilidade de coletar os dados, comparada com a ressonância magnética, torna o fNIRS ideal para investigações mais naturalísticas, mais próximas do que acontece na sala de aula.

$\mathrm{Na}$ busca de enfrentarmos o desafio de propormos experimentos menos artificias e mais próximos da sala de aula real desenhamos a simulação de uma aula de Astronomia para o Ensino Fundamental [81]. A chamamos de simulação pois havia apenas um estudante e a duração foi de 15 min, fora isso tudo seguiu como uma aula expositiva dialogada tradicional. Uma professora licenciada em Física interagiu com um aluno de 10 anos, usando uma lousa e discutindo com ele alguns conceitos básicos de Astronomia. Durante essa aula, coletamos os dados do rastreamento ocular juntamente com os dados do fNIRS na tentativa de evidenciar a exequibilidade de se obter dados confiáveis e robustos em ambientes mais próximos do cotidiano escolar. Mais que isso, buscamos investigar a possibilidade de medirmos, de maneira menos subjetiva, a atenção e engajamento do estudante durante uma aula. Para isso, focamos nossa análise no rastreamento ocular, nas variações do diâmetro das pupilas e nas redes frontoparietais do 
cérebro da criança, visto que elas estão envolvidas nos processos de controle de atencional. Nossos resultados revelaram uma sólida dinâmica de interação entre estas redes e a direção do olhar do estudante, mostrando que pesquisas dessa natureza, combinando diferentes instrumentos, podem trazer contribuições fundamentais para a compreensão dos processos de aprendizagem. Um resultado interessante diz respeito ao contato visual entre professor e aluno. Ainda que ele acompanhasse com atenção o que a professora desenhava na lousa, os momentos de maior engajamento e maior ativação das redes neurais aconteceram quando ele olhava para o rosto dela. Este resultado pode inspirar pesquisas futuras que conseguirão investigar de maneira inédita as interações em sala de aula.

Ainda em relação aos estudos acerca das interações professor-aluno, Brockington e colaboradores (2018) conduziram duas outras provas de conceito usando o fNIRS, agora com uma técnica conhecida como hyperscanning. Ela permite que sejam coletados dados de mais de um cérebro simultaneamente, em tempo real, permitindo assim investigar dinâmicas de interação entre sujeitos. Nesses dois experimentos investigamos a possível existência de uma sincronização entre os cérebros de professor e aluno durante o processo de ensino e aprendizagem de conceitos científicos. Para tanto, em um primeiro desenho experimental, uma professora trabalhou com uma criança de três anos uma tarefa desenhada para a aprendizagem de soma de dois números.
A criança já conseguia contar, contudo, ainda não sabia somar. Criamos um tabuleiro com uma pista na qual a aluna e a professora apostavam uma corrida a partir da soma dos números aleatórios que surgiam nas faces de dois dados que eram arremessados pela criança. Após o jogo dos dados, a criança separava um número de palitos de madeira correspondente à quantidade numérica de cada face dos dados. Depois, com auxílio da professora, a criança contava a quantidade total de palitos, efetuando a soma. Esse número final correspondia ao número de casas que um pequeno pedaço colorido de plástico percorreria na pista de corrida, como se fosse a aluna ou a professora. A dupla efetuou a tarefa diversas vezes, por mais de meia hora, com uma participação ativa e engajada da crença. Os dados da ativação cerebral de ambas foram coletados durante todo este processo. Nossos resultados revelaram sincronizações entre duas regiões cerebrais: o córtex pré-frontal, envolvido em processos cognitivos como contagem ou cálculo matemático, e a junção temporoparietal, associada diretamente com funções sociais, como empatia e mentalização. Assim, achamos uma sincronização entre a junção temporoparietal da professora com o córtex pré-frontal da criança, sugerindo um engajamento empático da docente com o esforço da aluna. Além disso, encontramos também uma correlação entre os córtices pré-frontais de ambas, apontando um alinhamento da atividade neural a professora e a aluna durante o processo de ensino e aprendizagem (Ver Figura 9).
A

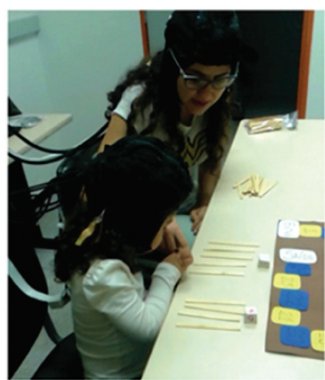

C
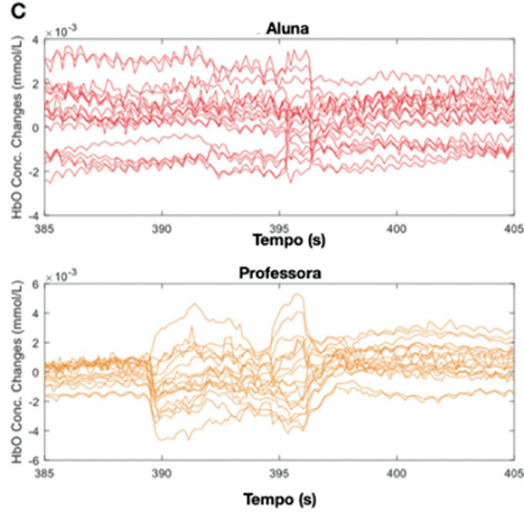

B

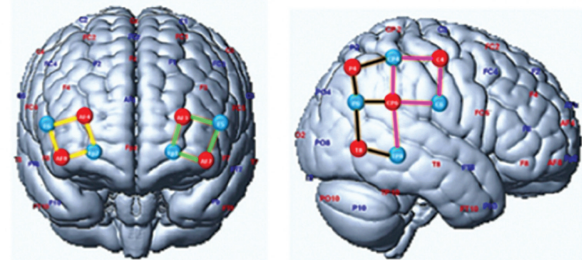

D

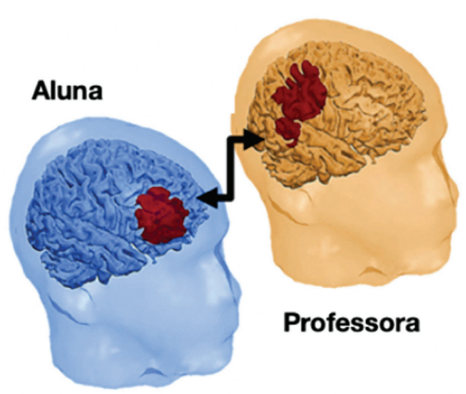

Figura 9: (A) Interação professora-aluna durante o jogo de contagem. (B) llustração de fontes (vermelho), detectores (azul) e canais agrupados em quatro regiões cerebrais: córtex frontal esquerdo (verde) e direito (amarelo), junção temporoparietal anterior (rosa) e posterior (marrom). (C) Exemplo de mudanças de concentração de $\mathrm{HbO}$ observadas para cada canal na aluna e na professora durante uma janela de tempo de 20 s. (D) Correlação significativa aluna-professora. Adaptado de [81]. 


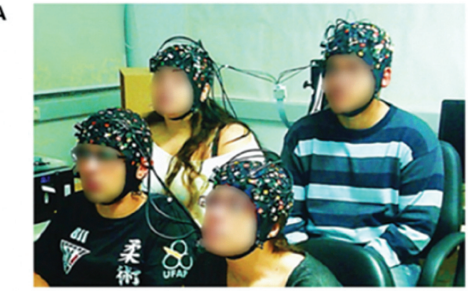

C
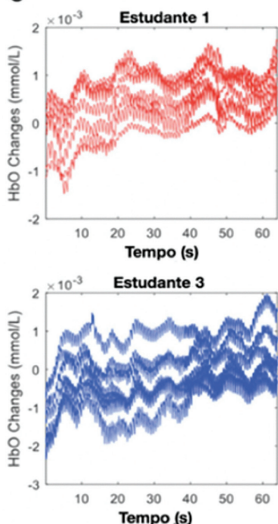
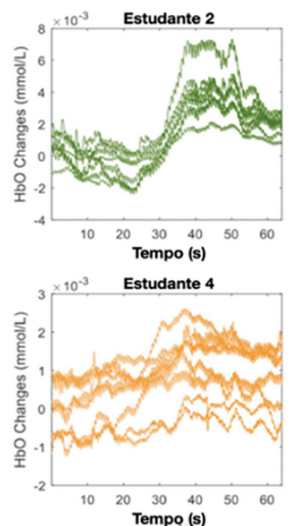

B

D
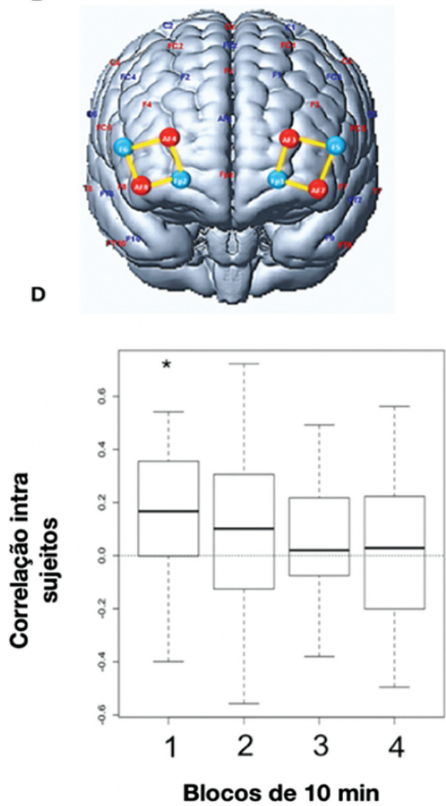

Figura 10: (A) Grupo de alunos assistindo à aula. (B) Ilustração de fontes (vermelho), detectores (azul) e canais (amarelo) sobre o córtex pré-frontal bilateral. (C) Exemplo de mudanças de concentração de $\mathrm{HbO}$ observadas nos canais de cada estudante durante uma janela de tempo de $60 \mathrm{~s}$. (D) Box-plots de correlações de $\mathrm{HbO}$ entre sujeitos nos quatro blocos de aula. A linha horizontal próxima ao meio de cada caixa indica a mediana, enquanto as bordas superior e inferior da caixa marcam o $25^{\circ}$ e $\circ 75^{\circ}$ percentis, respectivamente. $\mathrm{O}$ asterisco $(*)$ destaca uma diferença estatisticamente significativa. Adaptado de [81].

Por fim, investigamos a sincronização cerebral entre 4 estudantes de graduação assistindo a uma aula expositiva de $40 \mathrm{~min}$ de "Introdução à epigenética". O objetivo era verificar se as atividades cerebrais destes estudantes estavam sincronizadas e se seus estados de atenção e excitação variavam durante a aula. Para isso, medidos as atividades das redes neurais do córtex préfrontal bilateral em todo os sujeitos. Nossos resultados revelaram que a atividade cerebral dos quatro estudantes ficou sincronizada entre eles apenas durante os primeiros 10 minutos de aula, diminuindo na metade da aula e quase completamente dessincronizado ao final. Interpretamos que este resultado pode estar relacionado com a amplitude de atenção mais ampla dos alunos e níveis de excitação mais elevados no início da aula, que posteriormente vão diminuindo (Ver Figura 10 .

\section{Considerações Finais}

Foram apresentadas neste artigo diversas pesquisas que revelam o potencial do uso dos arcabouços teórico e metodológico da Neurociência para o tratamento de questões importantes e tradicionais no Ensino de Física. Inicialmente, é bastante inspirador perceber o quanto avançaram nos últimos anos as pesquisas acerca do processamento matemático no cérebro. É indiscutível a importância da cognição Matemática para a construção do pensamento físico 82 de modo que muito pode ser feito nessa interface, ainda tão pouco explorada nos trabalhos de Neurociência e Educação. Faltam estudos que, se fundamentando nesse rico conjunto de evidências já disponíveis sobre os mecanismos neuronais que dão suporte ao pensamento matemático, investiguem suas relações com o desenvolvimento e apropriação dos conteúdos que permitem a leitura Física do mundo.

Quando se trata especificamente de pesquisas que investigam o substrato neural que dá suporte à cognição Física, muito pouco foi realizado. Ainda assim, foi possível apresentar como temas velhos conhecidos no Ensino de Física, a modelagem, os modelos mentais, mudança conceitual e concepções alternativas, podem ser investigados pela Neurociência. Mais que isso, foram apresentadas as primeiras evidências de como estes elementos se dão no cérebro, mas, infelizmente, estes resultados são praticamente desconhecidos pelos pesquisadores da área, revelando a falta da interdisciplinaridade há tanto propagada em documentos oficiais, teses e dissertações.

Este artigo defende que a Neurociência pode contribuir enormemente para avançarmos na compreensão de diversos temas caros e importantes ao Ensino de Física e que vem sendo estudados da mesma forma há décadas. Considere, por exemplo, a persistência das concepções alternativas. Desde os anos 70 que já se conhece esse fenômeno e muito já foi pesquisado, com a proposição de modelos na tentativa de explicar tamanha estabilidade. Contudo, nenhum deles foi satisfatório para a compreensão total desta persistência. Assim, o 
que se pode encontrar hoje em pesquisas na área é apenas a afirmação de que elas existem, inviabilizando qualquer estratégia pedagógica eficaz de tratamento da questão justamente pela ausência de compreensão do mecanismo que as torna persistentes, ou o absurdo de se ainda produzirem dissertações e teses identificando-as, mesmo depois de 50 anos de pesquisas que praticamente esquadrinharam todos os conteúdos da Física. Seguese, assim, ignorando um dos maiores problemas com o qual todo docente se depara ao lecionar os conteúdos científicos.

Muitos resultados aqui apresentados podem ser utilizados para a elaboração de modelos atuais de mudança conceitual que, de fato, tratem da persistência das concepções alternativas ao invés de simplesmente constatá-las. Tem-se, agora, evidências acerca das principais áreas do cérebro relacionadas à mudança conceitual que podem contribuir para que as pesquisas no tema avancem. Os poucos exemplos aqui apresentados revelam o quanto ainda pode ser feito, evidências inéditas podem ser geradas ao se utilizar a Neurociência associada a tanto conhecimento sólido já produzido na área de Ensino de Física. Muito ainda deve ser aprofundado na compreensão da produção do pensamento causal complexo, do papel da memória de longo prazo, do controle inibitório, da detecção de erros, das funções executivas e dos aspectos afetivos e emocionais envolvidos na mudança conceitual. Há um vasto e excitante campo a ser explorado.

Ao se pensar nas simulações mentais das situações Física durante a aprendizagem um outro horizonte se abre. Praticamente nada se sabe sobre como tais simulações se processam em sujeitos com diferentes níveis de aprendizagem ou em diferentes populações. Alguns resultados apresentados neste artigo instigam o aprofundamento de estudos culturais mais amplos. Como será que tal influência se dá no cérebro? Quais os impactos das abordagens pedagógicas nesse processo? Qual o papel da cognição incorporada nestas simulações? Estas e outras perguntas seguem sem repostas.

Foram apresentados neste texto resultados preliminares sugerindo que regiões do cérebro ligadas ao raciocínio físico podem sofrer modificações ao longo de um semestre de instrução em Física. Assim, muito ainda deve ser feito para investigar os impactos reais das diferentes metodologias de ensino, bem como aprofundar o conhecimento acerca das diferentes estratégias de aprendizagem utilizadas pelos estudantes. Tais pesquisas podem contribuir para a elaboração de práticas pedagógicas baseadas em evidências concretas acerca da relação entre a aprendizagem do aluno e as mudanças de suas funções cerebrais, permitindo, assim, revolução similar à que foi produzida na aprendizagem de conteúdos de Matemática e Linguagem.

Foi possível revelar o potencial da Neurociência até mesmo em situações corriqueiras, como a disposição ou não de diagramas ou representações gráficas em questões de Física. A partir do uso de técnicas advindas das pesquisas em neuro foi possível investigar como estes elementos de design de uma questão orientam a atenção dos estudantes, propiciando o entendimento de como a forma de exibição acaba por impactar a compreensão de dados relevantes de um problema a ser solucionado. Quando os dados de medidas de um experimento são apresentados apenas em um formato numérico, o aluno precisa mobilizar mais recursos cognitivos para encontrar uma solução correta. Além disso, a crença que muitos professores têm sobre a importância de se colocar um diagrama apresentando a situação física a ser estudada pode acabar por prejudicar o aluno, retirando a atenção de pontos cruciais para a solução. A análise dos movimentos oculares fornece informações importantes sobre os processos cognitivos subjacentes à resolução de problemas de uma forma impossível de ser conseguida com os métodos tradicionais, que apenas fazem proposições a partir da pontuação dos estudantes. Estes pouquíssimos estudos com eye-tracking devem ser aprofundados e muito ainda precisa ser melhor compreendido sobre o tema, também virtualmente inexplorado na área de Ensino de Física.

Também foram apresentadas evidências sobre os impactos da ansiedade no cérebro, sugerindo que o ambiente emocional que as mulheres enfrentam na aprendizagem de conteúdos científicos pode ser ansiogênico desde o Ensino Fundamental, acarretando mudanças na ativação de suas redes neurais que podem ser detectadas na idade adulta, durante o Ensino Superior. Assim, de maneira mais ampla, este artigo trouxe três provas de conceitos que revelam o quanto as pesquisas em interação social em sala de aula podem avançar. Foram apresentadas evidências de como os cérebros de professor-aluno e aluno-aluno podem ficar sincronizados durante o processo de ensino e aprendizagem, revelando mecanismos ainda desconhecidos acerca destas interações. É indiscutível o papel do contexto social na Educação, mas muito ainda precisa ser compreendido. Desvelar os mecanismos neurais envolvidos nestas interações pode contribuir sobremaneira para a compreensão dos impactos emocionais e afetivos no contexto escolar, permitindo um aprofundamento necessário de um tema também muito pouco investigado no Ensino de Física.

O objetivo principal deste artigo foi chamar a atenção para a gama enorme de pesquisas que podem ser conduzidas na área, contribuindo para o aprofundamento de questões teóricas e práticas altamente relevantes para o Ensino de Física. Para isso, há a necessidade de uma integração, de fato, entre Neurociência, Psicologia e Educação. A expectativa de que um campo de pesquisa tão distante do contexto escolar apresente soluções rápidas e fáceis é tão ingênua quando falaciosa. Qualquer um que esteja debruçado de verdade sobre pesquisas na área compreende as inúmeras dificuldades em transladar os resultados de impressionantes imagens de ressonância magnética para a tarefa docente cotidiana. Essa visão 
da Neurociência e da Educação como panaceia faz parte da crença daqueles que são muito entusiasmados, logo iludidos, ou daqueles que lucram com a moda, logo charlatões. Além disso, há a necessidade de neurocientistas conversarem, de fato, com educadores pois, muitas vezes, há o anseio em responder perguntas sem sequer se questionar a pertinência destas mesmas perguntas no contexto escolar. Por outro lado, educadores precisam estar abertos ao que vem sendo produzido e considerar que, embora haja um esforço para desvendar os mecanismos neurais que dão suporte à aprendizagem, essa área de pesquisa não comunga de uma visão reducionista. Ninguém que pesquisa seriamente na interface destas três áreas tão complexas reduz a Educação a um emaranhado de disparo neuronal. Uma compreensão mais profunda acerca dos mecanismos de aprendizagem, que se dá a partir da combinação de achados neurocientíficos com teorias da Psicologia e da Educação, pode contribuir para a melhoria do processo de aquisição e uso do conhecimento científico, ajudando a repensar a Escola e seus processos educativos. Mas, sem a participação efetiva de pesquisadores em Ensino de Física pouco será realizado.

\section{Referências}

[1] U. Goswami, Nature reviews neuroscience 7, 406 (2006).

[2] M.H. Immordino-Yang e A. Damasio, Mind, brain, and education 1, 3 (2007).

[3] P.A. Howard-Jones, Nature Reviews Neuroscience 15, 817 (2014).

[4] M. Sigman, M. Peña, A.P. Goldin e S. Ribeiro, Nature neuroscience 17, 497 (2014).

[5] M.S. Thomas, D. Ansari e V.C. Knowland, Journal of Child Psychology and Psychiatry 60, 477 (2019).

[6] E.G. Jones e L.M. Mendell, Science 284, 739 (1999).

[7] U. Frith, D. Bishop, C. Blakemore, S.-J. Blakemore, B. Butterworth e U. Goswami, Neuroscience: implications for education and lifelong learning (The Royal Society, Londres, 2011).

[8] U. Goswami, Cognitive Development and Cognitive Neuroscience: The Learning Brain. (Routledge, 2019).

[9] J.T. Bruer, Educational researcher 26, 4 (1997).

[10] J.T. Bruer, CBE-Life Sciences Education 5, 104 (2006).

[11] J.T. Bruer, Nature Neuroscience 5, 1031 (2002).

[12] L. Waterhouse, Educational Psychologist 41, 207 (2006).

[13] N. Lahiri e J.S. Duncan, Epilepsy \& Behavior 11, 152 (2007).

[14] E.P. Jensen, Phi Delta Kappan 89, 408 (2008).

[15] J.A. Christodoulou e N. Gaab, Cortex 45, 555 (2009).

[16] M.R. Dougherty e A. Robey, Current Directions in Psychological Science 27, 401 (2018).

[17] M.S. Thomas, Current Directions in Psychological Science 28, 337 (2019).

[18] H.L. Roediger III, Psychological Science in the Public Interest 14, 1 (2013).

[19] S. Dehaene, M. Kerszberg e J.P. Changeux, Proceedings of the national Academy of Sciences 95, 14529 (1998).
[20] E. Temple e M.I. Posner, Proceedings of the National Academy of Sciences 95, 7836 (1998).

[21] B. Röder, F. Rösler e H.J. Neville, Neuropsychologia 38, 1482 (2000).

[22] S. Dehaene, M. Piazza, P. Pinel e L. Cohen, Cognitive neuropsychology 20, 487 (2003).

[23] C. Pallier, S. Dehaene, J.B. Poline, D. LeBihan, A.M. Argenti, E. Dupoux e J. Mehler, Cerebral cortex 13, 155 (2003).

[24] G. Dehaene-Lambertz, L. Hertz-Pannier, J. Dubois e S. Dehaene, European Review 16, 399 (2008).

[25] S. Dehaene, F. Pegado, L.W. Braga, P. Ventura, G. Nunes Filho, A. Jobert, G. Dehaene-Lambertz, R. Kolinsky, J. Morais e L. Cohen, Science 330, 1359 (2010).

[26] N.M. Raschle, J. Zuk e N. Gaab, Proceedings of the National Academy of Sciences 109, 2156 (2012).

[27] OECD/CERI International Conference in "Learning in the $21^{\text {st }}$ Century: research, innovation and policy", Understanding the Brain: the Birth of a Learning Science (2008).

[28] U. Goswami, British Journal of Educational Psychology 74, 1 (2004).

[29] D. Szűcs e U. Goswami, Mind, Brain, and Education 1, 114 (2007).

[30] M.I. Posner e M.K. Rothbart, Trends in cognitive sciences 9, 99 (2005).

[31] E.R. Kandel, J.H. Schwartz, T.M. Jessell, D.O. Biochemistry, M.B.T. Jessell, S. Siegelbaum e A. Hudspeth, Principles of neural science (McGraw-hill, New York, 2000), v. 4.

[32] B. Roder e H. Neville, Handbook of neuropsychology 9, 231 (2003).

[33] T. Gisiger, M. Kerszberg e J. P. Changeux, Cerebral Cortex 15, 489 (2005).

[34] M.S. Gazzaniga, R.B. Ivry e G. Mangun, Cognitive Neuroscience: the biology of the mind (Norton, New York, 2006).

[35] S.J. Blakemore e U. Frith, The learning brain: Lessons for education (Blackwell publishing, 2005).

[36] B. Draganski, C. Gaser, V. Busch, G. Schuierer, U. Bogdahn e A. May, Nature 427, 311 (2004).

[37] S. Dehaene, E. Spelke, P. Pinel, R. Stanescu e S. Tsivkin, Science 284, 970 (1999).

[38] B. Luna, K.R. Thulborn, D.P. Munoz, E.P. Merriam, K.E. Garver, N.J. Minshew, M.S. Keshavan, C.R. Genovese, W.F. Eddy e J.A. Sweeney, Neuroimage 13, 786 (2001).

[39] S.L. Bengtsson, Z. Nagy, S. Skare, L. Forsman, H. Forssberg e F. Ullén, Nature Neuroscience 8, 1148 (2005).

[40] S.M. Rivera, A. Reiss, M.A. Eckert e V. Menon, Cerebral Cortex 15, 1779 (2005).

[41] T.W. Buchanan e D. Tranel, Neurobiology of learning and memory 89, 134 (2008).

[42] E.A. Kensinger e D.L. Schacter, Memory and emotion, disponível em: https://citeseerx.ist.psu.edu/viewdoc/ download?doi=10.1.1.1084.2301\&rep=rep1\&type=pdf (2008).

[43] M. Nishida, J. Pearsall, R.L. Buckner e M.P. Walker, Cerebral Cortex 19, 1158 (2009)

[44] P.S. Jacques, F. Dolcos e R. Cabeza, Neurobiology of aging 31, 315 (2010). 
[45] M. Pietrocola, Caderno brasileiro de ensino de física 19 93 (2002)

[46] T. Dantzig, Number: The language of science (Penguin Books, Londres, 2007).

[47] L. Feigenson, S. Dehaene e E. Spelke, Trends in cognitive sciences 8, 307 (2004).

[48] J.F. Cantlon, M.E. Libertus, P. Pinel, S. Dehaene, E.M. Brannon e K.A. Pelphrey, Journal of cognitive neuroscience 21, 2217 (2009).

[49] S. Dehaene, The number sense: How the mind creates mathematics (Oxford University Press USA, Jericho, 2011).

[50] D.M. Rumbaugh, S. Savage-Rumbaugh e M.T. Hegel, Journal of Experimental Psychology: Animal Behavior Processes 13, 107 (1987).

[51] L. Piffer, C. Agrillo e D.C. Hyde, Animal cognition 15 215 (2012).

[52] S.R. Howard, A. Avarguès-Weber, J.E. Garcia, A.D Greentree e A.G. Dyer, Proceedings of the Royal Society B 286, 20190238 (2019).

[53] A. Karmiloff-Smith, International Journal of Language \& Communication Disorders 29, 95 (1994).

[54] K. Wynn, Nature 358, 749 (1992).

[55] F. Xu e E.S. Spelke, Cognition 74, B1 (2000).

[56] F. Xu, Cognition 89, B15 (2003).

[57] K. McCrink e K. Wynn, Psychological Science 15, 776 (2004).

[58] F. Xu, E.S. Spelke e S. Goddard, Developmental science 8, 88 (2005)

[59] S. Cordes e E.M. Brannon, Developmental Science 11, $803(2008)$

[60] F. Xu e R.I. Arriaga, British Journal of developmental psychology 25, 103 (2007).

[61] J.S. Lipton e E.S. Spelke, Psychological science 14, 396 (2003).

[62] J.N. Wood e E.S. Spelke, Developmental science 8, 173 (2005).

[63] V. Izard, G. Dehaene-Lambertz e S. Dehaene, PLoS Biol 6, e11 (2008).

[64] J. Christodoulou, A. Lac e D.S. Moore, Developmental Psychology 53, 1405 (2017).

[65] A. Berger, G. Tzur e M.I. Posner, Proceedings of the National Academy of Sciences 103, 12649 (2006).

[66] Y. Tang, W. Zhang, K. Chen, S. Feng, Y. Ji, J. Shen, E.M. Reiman e Y. Liu, Proceedings of the National Academy of Sciences 103, 10775 (2006).

[67] S. Dehaene e L. Cohen, Mathematical cognition 1, 83 (1995).

[68] J.L. Parsons, N.E. Marchand-Martella, K. WaldronSoler, R.C. Martella e B. Lignugaris-Kraft, Journal of Direct Instruction 4, 95 (2004).

[69] S. Griffin, in Early intervention for children at risk of developing mathematical learning difficulties (Brookes Publishing Co, 2007).

[70] R.S. Siegler e G.B. Ramani, Developmental science 11 655 (2008).

[71] L.A. Kroeger, R.D. Brown e B.A. O'Brien, Early Education \& Development 23, 37 (2012).

[72] R.A. Mason e M.A. Just, NeuroImage 111, 36 (2015).
[73] R.A. Mason e M.A. Just, Psychological science 27, 904 (2016).

[74] E. Brewe, J.E. Bartley, M.C. Riedel, V. Sawtelle, T. Salo, E.R. Boeving, E.I. Bravo, R. Odean, A. Nazareth, K.L. Bottenhorn et al., Frontiers in ICT 5, 10 (2018).

[75] E. Brewe. American Journal of Physics 76, 1155-1160 (2008).

[76] D. Hestenes, M. Wells e G. Swackhamer, The physics teacher 30, 141 (1992).

[77] J.E. Bartley, M.C. Riedel, T. Salo, E.R. Boeving, K.L. Bottenhorn, E.I. Bravo, R. Odean, A. Nazareth, R.W. Laird, M.T. Sutherland et al., npj Science of Learning 4, 1 (2019).

[78] L.M.B. Foisy, P. Potvin, M. Riopel e S. Masson, Trends in Neuroscience and Education 4, 26 (2015).

[79] A.A. Gonzalez, K.L. Bottenhorn, J.E. Bartley, T. Hayes, M.C. Riedel, T. Salo, E.I. Bravo, R. Odean, A. Nazareth, R.W. Laird et al., npj Science of Learning 4, 1-10 (2019).

[80] A. Susac, A. Bubic, P. Martinjak, M. Planinic e M. Palmovic, Physical Review Physics Education Research 13, 020125 (2017).

[81] G. Brockington, J.B. Balardin, G.A.Z. Morais, A. Malheiros, R. Lent, L.M. Moura e J.R. Sato, Frontiers in psychology 9, 1840 (2018).

[82] M. Paty, Matéria Roubada (Edusp, São Paulo, 1995), v. 8. 